\title{
EL PODER DE LOS ECONOMISTAS
}

y los economistas del poder

\author{
MARCELA Rozo TORRES \\ INVESTIGADORA INDEPENDIENTE \\ mar.rozo@gmail.com
}

\begin{abstract}
Resumen
[ STE ARTÍCULO, UN EJERCICIO SOBRE LA ANTROPOLOGÍA DEL PODER, TOMA COMO EJEMPLO [ a un grupo de economistas colombianos que en las últimas décadas han sustentado altos cargos en el gobierno nacional. El trabajo está dividido en dos partes. La primera se centra en la argumentación teórica que hace de la economía una ciencia social con un poder particular, sirviendo esto como justificación para tomar a los economistas como objeto de estudio. En la segunda se hace un recorrido por las prácticas que marcan el camino al poder, paralelo a un análisis del discurso mediante entrevistas a algunos economistas. Esto último con miras a descubrir el elemento ideológico de los argumentos utilizados por estos en el ejercicio de legitimación del círculo de poder.
\end{abstract}

PALABRAS CLAVE: antropología del poder, círculos de poder, economistas, economía.

\begin{abstract}
T HIS ARTICLE IS AN EXERCISE IN THE ANTHROPOLOGY OF POWER WITHIN A GROUP OF COLOMbian economists who held top positions in government in the last 20 years. It is divided into two sections: The first section focuses on the theoretical premises that make economics a social science with particular power. In turn, this position allows me to examine economists as distinct objects of study. The second section describes practices determining routes to power and offers a discursive analysis of interviews held with these economists. The aim of this analysis is to uncover the ideological element behind arguments used by these economists to legitimize their circle of power.
\end{abstract}

KEY wORDS: Anthropology of power, circles of power, economists, economics.

$\frac{\text { Rvista Colom bianade Antropologia }}{\text { Volumen 42, enero-diciembre 2006, pp. 277-316 }}$




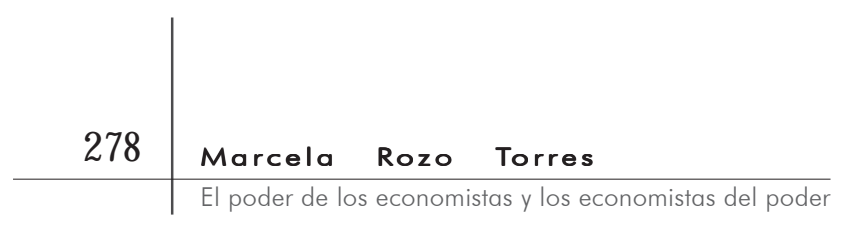

\section{INTRODUCCIÓN*}

STE TRABAJO SURGE DEL INTERÉS EN LAS RELACIONES DE PODER Y EN - las formas culturales que lo permiten. A simple vista, se po- dría afirmar que utilizar como objeto de estudio a economistas con un perfil particular es una de las tantas maneras de acercarse al estudio del poder, en especial cuando este deja de estar

* Agradezco muy especialmente a Hernando Matallana, quien ha sido el mejor guía y el gran impulsor para materializar la inquietud personal que rodea este trabajo. Y a Sanjay, por supuesto. Agradezco también por sus comentarios a los evaluadores anónimos y a la Revista. un fenómeno que probablemente se presenta de manera similar en todos los gremios. Sin embargo, el área de estudio de esta disciplina la ubica en una posición privilegiada, y eso hace que los economistas como círculo de poder aparezcan como un fenómeno particularmente interesante.

Por su capacidad para explicar buena parte de las relaciones sociales, y por su exclusividad como ciencia social cuantitativa, la economía como saber se ha establecido como una herramienta de poder, una herramienta que controla y, por eso mismo, quiere ser y es controlada por quienes manejan el discurso económico dominante. No obstante, la monopolización institucional del discurso económico sólo empieza a hacerse visible cuando los economistas de profesión se convierten en piezas fundamentales de los gobiernos nacionales, para el diseño y puesta en marcha de políticas públicas y para el diálogo económico entre los gobiernos de distintos estados nacionales. Para la economía en tanto disciplina, este desarrollo significó la expansión de su influencia y su transformación en un saber que se reafirma como exclusivo de los economistas de profesión, al requerirse de un conocimiento cada vez más técnico.

Lo anterior se refuerza con la adjudicación de los altos cargos económicos en el estado. No obstante, observa Palacios, dicho proceso "no parece guiarse por los principios ciudadanos de la igualdad de oportunidades, sino por la lógica de la reproducción del capital cultural de los grupos sociales dominantes" (Palacios, 2001). La constatación de Palacios nos lleva a pregun- 


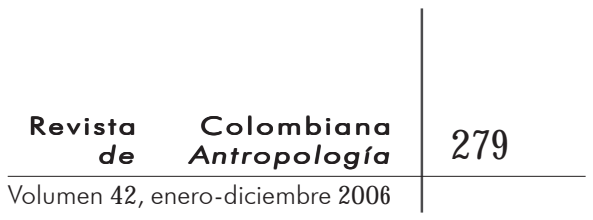

tarnos por los mecanismos que permiten la reproducción de este círculo formado por la economía como forma discursiva y práctica de poder, de una parte, y los economistas como agentes en y del poder, de otra.

Este trabajo busca indagar acerca de la creación y recreación de estas relaciones de poder en Colombia, tomando como ejemplo las dos últimas décadas del siglo veinte. Para empezar el análisis es necesario tener presente que ahondar en el estudio de las relaciones de poder supone cuestionar y desnaturalizar los discursos dominantes, para desvelar su estructura, fundamentos y justificaciones (Dirks et al., 1994). Analizar el discurso expresado por los economistas del poder permite entender dos asuntos: primero, cómo se crean y recrean las relaciones dentro de este grupo; y segundo, las relaciones de poder que ejercen los economistas sobre el resto de la sociedad.

El análisis parte de suponer que los discursos sólo son posibles gracias a las prácticas que constituyen las realidades sociales y, en tal sentido, estas prácticas determinan quién habla y qué dice. De manera que entender un discurso significa comprender las prácticas que lo soportan. Hacer su etnografía no es interpretar un saber particular, sino descubrir la lógica de una práctica concreta, los modos sociales y culturales que permiten ese saber, convirtiéndose en pregunta central para leer el discurso quién habla y desde dónde se pronuncia.

La primera parte de este artículo se centra en la argumentación teórica que hace de la economía una ciencia social con un poder particular; es la justificación para tomar a los economistas como objeto de estudio. La segunda se centra, primero, en la identificación de los economistas del poder, y, segundo, en un recorrido por las prácticas que marcan el camino al poder. Es claro que estas prácticas se refieren al quehacer de la disciplina como tal, y al lugar que ocupan en la sociedad, a los ritos y procesos -académicos y sociales- que deben cumplir quienes pretenden acceder a esta esfera del poder.

Transversal a esto se analiza el discurso mediante entrevistas a algunos economistas, para descubrir el elemento ideológico de los argumentos que utilizan ellos mismos en el ejercicio de legitimación del círculo de poder al que pertenecen, no muy amplio, y que contribuyen a reproducir rotándose en los altos cargos de las instituciones económicas. 


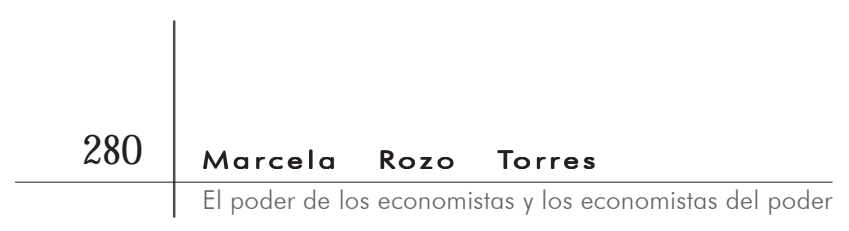

EL PODER DE LA ECONOMÍA

L DISCURSO ECONÓMICO HA LOGRADO ESTABLECER UNAS BASES TEÓRICAS

? e ideológicas que le permiten situarse en un lugar privile-

- giado dentro del orden normativo del discurso como una herramienta de poder, tanto de ordenamiento social como de justificación y legitimación de políticas públicas promovidas por el gobierno de turno desde el estado.

Para comprender la fuerza que ha logrado cobrar esta disciplina como relación de poder, particularmente el discurso económico liberal, es necesario remitirse a la historia del pensamiento económico. Ello por cuanto sólo mediante la reflexión crítica del desarrollo del discurso económico es posible entender los cambios ideológicos necesarios para el establecimiento de esta forma de conocimiento como una ciencia que busca explicar el comportamiento humano cuantificable, con el objeto de predecirlo y, de ese modo, promulgar la normativa de una sociedad capitalista. No obstante, debe advertirse que la crítica interna de las teorías clásica y neoclásica en tanto teorías económicas no es y no puede ser objeto de este escrito.

La economía política clásica que surgió en los siglos dieciocho y diecinueve se puede considerar el progenitor más cercano e importante del discurso económico liberal moderno. En palabras de Milton Friedman, el movimiento intelectual que se desarrolló a finales del siglo dieciocho y principios del diecinueve bajo el nombre de liberalismo, "daba importancia a la libertad como meta final y al individuo como entidad superior de la sociedad" (1962: 17). Estas resultan ser las condiciones necesarias para el desarrollo de un sistema de propiedad privada en el que toda persona está en capacidad de generar su propia riqueza (Cataño, 1999. Q2).

Las habilidades necesarias para la generación de riqueza material son las facultades o talentos dados por la naturaleza para conseguir la supervivencia, abstraídas bajo el concepto de la fuerza de trabajo que posee cada individuo, pues son justamente dichas habilidades, vistas como trabajo, las que son importantes como fuente de riqueza en el sistema capitalista. El desarrollo social de dicha riqueza como valor de cambio supone las propensiones naturales del ser humano, entendidas como la tendencia a "trocar, permutar y cambiar una cosa por otra" (Smith, 1776. Se alude así a la búsqueda y necesidad que tienen los seres 


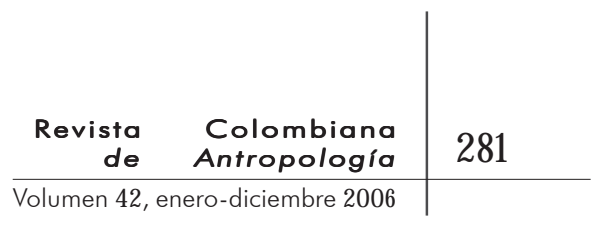

humanos de relacionarse con otros, y el intercambio de mercancías sería la expresión social por excelencia de esta propensión.

En la economía política clásica se considera que la riqueza se encuentra en las mercancías, y su fuente de valor es el trabajo en general, como relación social y económica. El hecho de atribuirle al trabajo el poder de generar riqueza en la sociedad capitalista permite fundar teóricamente un sistema natural de la libertad. De este modo puede conciliarse el capitalismo con la idea del individuo como agente libre y autónomo: libre para tomar decisiones sobre la producción y el consumo, y autónomo en el hecho de que al poseer su fuerza de trabajo el ejercicio de su libertad no depende de otros ni de condiciones externas ${ }^{1}$.

La lectura crítica del postulado liberal advierte que el fundamento de la economía liberal en el individualismo es, en parte, respuesta a la necesidad de encontrar una alternativa al sistema mercantilista, en el que la economía está inmersa en las instituciones y la política. Como respuesta a este sistema, la filosofía liberal pretende que la economía se aleje del vicio político, justificándola en el comportamiento individual

1 Es importante tener en cuenta que en el momento en que la economía política clásica formuló su teoría, existía ya el concepto de individuo libre. La presencia de proposiciones desde la filosofía política liberal, como las de John Locke, en las que el estado natural del ser humano es "un estado de completa libertad para ordenar sus actos, y para disponer de sus propiedades y de sus personas como mejor le parezca, dentro de los límites de la ley natural, sin necesidad de pedir permiso, y sin depender de la voluntad de otra persona" (Locke, 1690: 32), sirven de fundamento para diseñar un ordenamiento social, político y económico con el individuo libre como su premisa y autorregulado por su propia acción.

y no en el social. Si bien es cierto que el mercado en su forma capitalista y su reglamentación se desarrollaron de la mano, ya que en el momento en el que los mercados se desplegaron con mayor fuerza lo hicieron bajo la dirección de una administración centralizada del sistema mercantilista (Polanyi, 1944: 121), tampoco es menos cierto que la teoría política clásica busca aislar totalmente la economía de la perversión política del soberano. De modo tal que la realización de ese proyecto político hace necesaria una teoría económica que represente al capitalismo como un sistema regido, regulado y orientado únicamente por el funcionamiento del mercado, es decir, por un regulador natural que asegura la igualdad de condiciones para quienes participen en él.

El contenido normativo del proyecto liberal es no sólo la división institucional de la sociedad en una esfera económica y 


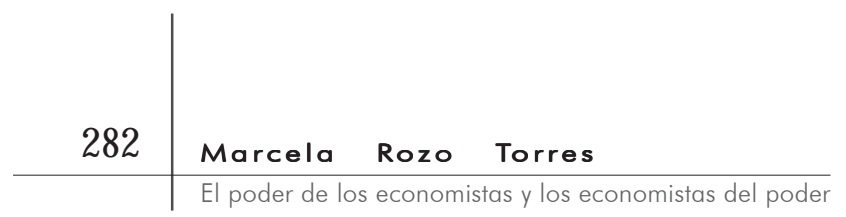

una esfera política, sino también una "sociedad gestionada en tanto que auxiliar del mercado" y, por tanto, de relaciones sociales encasilladas en el sistema económico, y no viceversa (Polanyi, 1944: 104). Se promueve así la dicotomía entre un mundo de agentes económicos sin instituciones y un mundo de agentes institucionalizados, logrando con los primeros una ficción teórica que sirve como base al individualismo metodológico. En ella "lo social se halla en última instancia en los individuos definidos antes de ser sociables" (Cataño, 1999. 59) de modo tal que el individuo es, antes que agente social, un ente natural.

La economía política clásica elabora una teoría sustentada en individuos que materializan el ejercicio de su libertad en los mercados: los sujetos económicos acuden al mercado con la certeza de realizar los excedentes de su trabajo y, así mismo, con la intención de adquirir los excedentes de otros individuos con miras a satisfacer sus necesidades. Con esta elaboración teórica nos encontramos ante la oferta y demanda de múltiples individuos que, al buscar su bienestar personal, promueven simultáneamente la satisfacción de las necesidades ajenas.

El resultado social de la acción de los múltiples individuos que conforman la sociedad es todo un ciclo económico de producción, distribución, cambio y consumo, mediado por el sistema de mercados de la economía.

Dicha economía implica la existencia de mercados en los que la oferta de bienes disponibles (comprendidos los servicios) a un precio determinado será equivalente a una demanda de igual precio; supone la presencia del dinero que funciona como poder adquisitivo en las manos de quien lo posee. La producción se regirá, pues, por los precios, ya que de los precios dependen los beneficios de quienes orientan la producción; y también la distribución de bienes dependerá de los precios, pues los precios conforman los ingresos, y gracias a ellos los bienes producidos son distribuidos entre los miembros de la sociedad. Si se admiten estas hipótesis, tanto la producción como la distribución de los bienes quedan aseguradas únicamente por los precios (Polanyi, 1944: 22).

En dicho sistema el precio de mercado de la mercancía tiene como función única la resolución, de manera imparcial bajo condiciones de libre competencia, de los intereses opuestos de los agentes económicos que actúan en el mercado como compradores y vendedores. Este postulado es central y definitivo, 


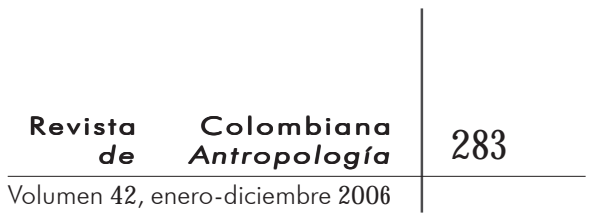

por cuanto de aquí se desprende que en las relaciones sociales no hay, inicialmente, una relación de poder, sino que gracias al mercado y a algo tan neutral como los precios definidos por oferta y demanda todos los agentes están en igualdad de condiciones para satisfacer sus necesidades y, por tanto, son libres de escoger dado el precio.

Ahora bien, en este punto es indispensable tener presente, en particular en lo que toca a la teoría del valor, que en el caso de la economía clásica el proceso económico incorpora precios relativos, como una proporción de cambio entre bienes, determinados por las condiciones materiales de la producción. En contraste, en el caso de la economía neoclásica la relación de cambio de los bienes será resultado de la escasez relativa de los mismos. No obstante fundarse en principios económicos distintos, en ningún caso el dinero tiene papel esencial alguno en la teoría del valor, una teoría cuyo contenido es, irónicamente, la determinación de la relación de cambio de las mercancías en una economía caracterizada por relaciones sociales monetarias.

La abstracción del dinero como relación económica y su evacuación como forma fenoménica de los precios tiene consecuencias profundas para la concepción clásica-neoclásica del capitalismo. Por un lado, la negación del dinero como el nexo social del capitalismo implica en última instancia la ausencia de relaciones sociales y, por tanto, la naturalización de la economía, o más precisamente de las relaciones económicas establecidas en el mercado. Por otro, la evacuación del dinero como la forma general del valor hace necesaria la invención de un sistema de magnitudes económicas, es decir, de una nomenclatura ajena a la forma social de la propiedad privada, el precio monetario. La negación del dinero como nexo social en la ortodoxia clásica y neoclásica trae consigo el surgimiento de teorías del valor y de los precios que promueven la imagen de un mundo autorregulado, natural y sin determinación monetaria alguna, dándole la oportunidad a la disciplina económica de crearse un mundo más allá de la política, de los intereses extraeconómicos y, de esta forma, acercarse, tal es su pretensión, a un conocimiento más objetivo.

Sin embargo, si bien el dinero es totalmente eliminado de las teorías clásica y neoclásica del valor y de los precios, su presencia sigue siendo indispensable para la existencia de una economía de intercambio, convirtiéndose así en un mal necesario. Necesario porque, dadas las dificultades inherentes al trueque, 


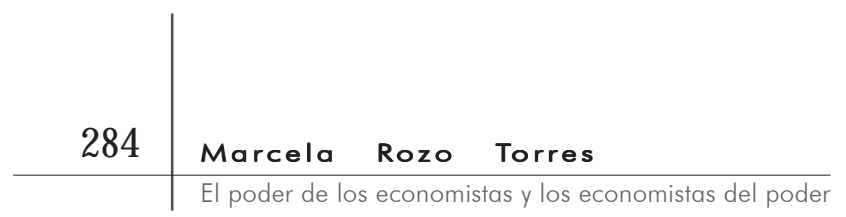

su presencia es imprescindible para la existencia del intercambio. Y mal, porque implica la presencia del estado, al aceptarse que la emisión debe estar en sus manos, lo que hace obligatoria la presencia de la política como un elemento de su regulación, y, por tanto, la posibilidad del abuso y de la violación de las libertades del individuo (Cataño, 1999. 72).

De manera que, aun cuando se acepte que la emisión de la moneda debe permanecer en manos del gobierno central, sí es posible eliminar, desde el campo de la teoría, la capacidad del dinero de regular relaciones sociales, lo que no es otra cosa que despojarlo de todo su poder. Entonces, ¿cómo se concilia el problema de la existencia de gobiernos nacionales cuando la teoría establece que el mercado permite el funcionamiento del sistema natural de la libertad y que el estado y las instituciones políticas son propensos a perjudicar esa libertad?

Es evidente que el dinero está asociado de hecho, históricamente, al Príncipe y al conjunto de las instituciones políticas (Benetti y Cartelier, 1998: 14). El dinero regula relaciones sociales en la medida que el Príncipe o las instituciones políticas lo pueden emitir y exigir a su vez en forma de impuestos, haciendo que la producción -luego todo el ciclo económico- de los individuos esté condicionada a la consecución del dinero necesario para pagar la deuda o impuesto. He aquí su poder, y he aquí la razón por la cual la teoría busca separar al Príncipe del dinero, y a la vez eliminarlo como el nexo social.

Evitar que el Príncipe socave la estabilidad del proceso económico por medio de la destrucción de la propiedad privada mediante la emisión arbitraria de moneda exige dos actos: primero, quitarle al soberano el derecho del monopolio de emisión y su poder de decisión sobre el gasto público; y, segundo, legitimar ese primer acto mediante la formulación de un argumento científico que muestre la necesidad de una política monetaria, cambiaria y fiscal independiente del soberano y que se rija por un principio de racionalidad económica. Esto último se logra por medio de la formulación de una teoría económica que separa el sistema de mercado autorregulado y la política monetaria, es decir, que crea una dicotomía en los precios y el dinero. Así, aun cuando se acepte que la existencia de un gobierno es necesaria "para mantener nuestras libertades", esto no significa que no se busque reducir su poder al mínimo, aduciendo que los posibles abusos resultantes de "la concentración del poder en 


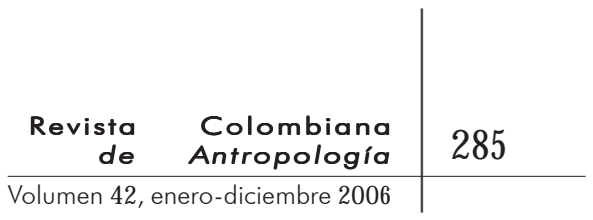

manos políticas es también una amenaza a la libertad" (Friedman, 1962: 14). En este sentido, "el rechazo de toda base monetaria de la teoría del valor aparece bastante lógico” (Benetti y Cartelier, 1998: 14). La separación de la esfera real y la esfera monetaria hace que la economía no esté viciada por la política, $\mathrm{y}$, por tanto, que sirva de sustento del capitalismo como el sistema natural de la libertad, y al mercado, fundamento del sistema capitalista, como algo autorregulado y natural.

En este contexto, la importancia de la evacuación del dinero de la teoría del valor y de los precios debe ser entendida desde dos puntos diferentes: uno teórico -el problema de lo real y lo monetario-, y uno político -la separación de la economía de lo político, lo institucional y el poder soberano-, que en realidad terminan siendo dos caras de un mismo problema. Como veíamos, la economía política clásica busca eliminar los nexos que existían bajo el sistema mercantilista entre las instituciones políticas y las económicas: el soberano, y más tarde los gobiernos nacionales, van a representar una clara amenaza, tanto para la filosofía liberal como para la economía como ciencia, pero también para la libertad económica entendida como la autonomía del individuo de disponer libremente sobre su propiedad privada.

Resumamos. La teoría monetaria clásica y neoclásica -monetarismo-consideran que el sistema de precios se autorregula, pero que el manejo del dinero dejado al arbitrio de la voluntad política del soberano hace imposible cualquier proceso de autorregulación del mercado. La consideración teórica del dinero en la economía clásica y neoclásica se presenta como un momento posterior a la determinación teórica del valor. Esta incorporación ex post del dinero tiene su expresión en el carácter esencialmente neutral del mismo en el proceso económico. Dicha neutralidad implica una separación dicótoma entre el mundo real y el mundo monetario. En el primero, el mercado se autorregula por medio del sistema de precios relativos, en tanto que en el segundo el dinero tiene como única función facilitar el intercambio sin llegar nunca a estructurarlo y hacer de los precios relativos precios monetarios. En el mundo real es donde los individuos se relacionan, intercambian y transan, y a partir de esta relación se construye el mundo monetario.

En cuanto al estado, ambas teorías tienden a ver con recelo cualquier función que este desempeñe, ya que "el poder para 


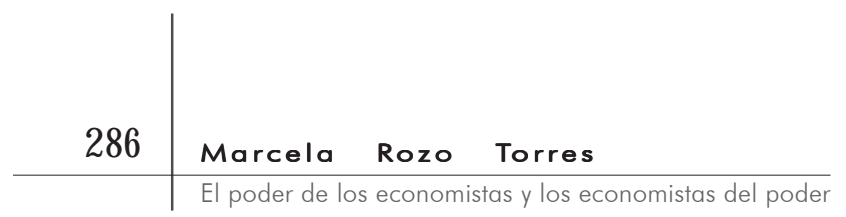

hacer el bien es también el poder para perjudicar" (Friedman, 1962: 15). Admiten, eso sí, que debe establecer las leyes básicas de la sociedad, velar por su cumplimiento y crear un marco en el que las empresas puedan competir libremente entre sí (Stiglitz, 1993 191). Se acepta pues que el estado debe determinar las reglas de juego, aun cuando el ideal es dejar actuar al mercado para que "reduzca el número de cuestiones que hay que decidir por medios políticos y, por lo tanto, minimiza la participación del gobierno en el juego" (Friedman, 1962: 30).

En cuanto a la política económica en particular, tiene como función exclusiva garantizar, por una parte, la vigencia de la institución del libre mercado por medio de medidas antimonopolio y de desregulación, y, por otra, la estabilidad de la economía en su conjunto mediante políticas de carácter macroeconómico. En este último caso, la necesidad de una regulación del dinero hace inevitable que la autoridad monetaria y el gobierno sean los encargados de la política macroeconómica -monetaria, cambiaria y fiscal- necesaria para la estabilidad económica, concertada entre la banca central y la hacienda pública bajo el tecnicismo de "programación macroeconómica".

La necesidad de la intervención estatal mediante políticas públicas de carácter económico exige la presencia de economistas de profesión en la esfera pública, de técnicos capaces de dar razón de esos fenómenos, de tomar las decisiones adecuadas y de manejar esas decisiones por fuera de los intereses políticos. Lo que lleva no sólo al fortalecimiento de la disciplina gracias a su carácter indispensable en la toma de decisiones estatales, sino a la creación de un grupo que, más allá de realizar una labor puramente técnica, tiene en sus manos un enorme poder. Es gracias a que la ciencia económica sea presentada como natural, positiva y desinteresada, que los economistas pueden justificar sin mayor resistencia sus decisiones detrás de una argumentación técnica, sustentada, en apariencia, en su discurso científico libre de juicios de valor y por encima de intereses particulares, haciéndose así incuestionables y objetivos en el ejercicio del poder.

Este trabajo busca hacer explícito el hecho de que, en la medida que la economía es creada y recreada -deliberadamente o no- por el ser humano, su estructura, procesos, operaciones y consecuencias no son algo natural o dado de antemano, sino que son un producto del actuar social (Samuels, 1988: 348). Por 


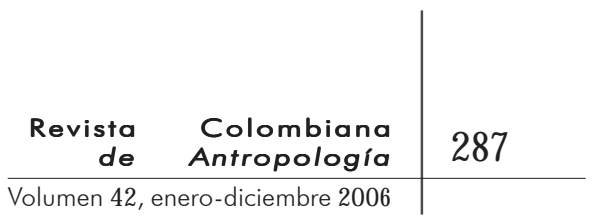

esto mismo, y teniendo en cuenta el poder que tiene en la estructuración de procesos sociales, es necesario entenderla como una herramienta de poder y de control social.

\section{LOS ECONOMISTAS DEL PODER}

\section{Antecedentes}

P L FENÓMENO DE LOS ECONOMISTAS COMO POSEEDORES DE SABER-PODER $\sqcup$ está enmarcado en los sistemas que definen la modernidad, particularmente el mercado y el sistema mundial. Este poder empieza a estructurarse con el resurgimiento de las ideas de libertad y la formalización de la economía clásica en el siglo dieciocho, y logra consolidarse especialmente durante y después de la guerra fría en el siglo veinte, lo cual significará la articulación y el fortalecimiento de un nuevo discurso que tiene grandes incidencias sobre lo económico y lo político (Escobar, 1988: 433 ).

En Latinoamérica particularmente, en el periodo de la guerra fría la táctica consistió en adelantar una política de "amigos de América”, y en exportar hacia estos países conocimiento estadounidense, en especial pero no sólo económico. La desintegración de los regímenes comunistas se entendía como la demostración definitiva de que las relaciones sociales estructuradas a partir de la voluntad política no podían competir con las relaciones sociales estructuradas por el mercado (Markoff y Montecinos, 1994: 25), dando pie a un auge sin precedentes del sistema de mercado y de una élite comprometida con este.

Fue así como los esfuerzos se orientaron a crear una tecnocracia capaz de ser competente y reformista a la vez, y que pudiera evitar la polarización del campo político entre ultraconservadores de derecha e izquierdistas radicalizados que actuaran como revolucionarios. Un claro ejemplo de esto fue la Alianza para el progreso, entendida como una alianza entre élites profesionales al servicio de una política que promovía la modernización, convirtiéndose, a su vez, en un antídoto para el comunismo (Dezalay y Garth, 2002: 108).

A pesar de la fuerza que cobró esta disciplina a lo largo de la guerra fría, la economía como profesión ya había venido adquiriendo importancia en Colombia desde finales de los años 1930, 


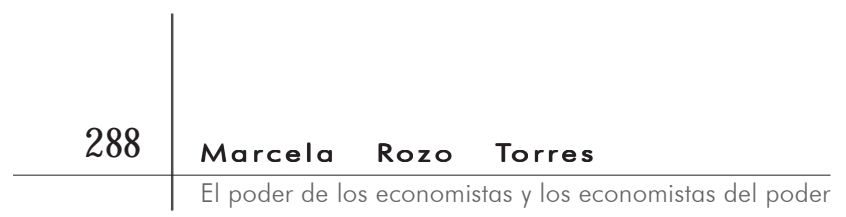

desplazando a profesiones más antiguas, como el derecho o la ingeniería, de las tareas ejecutivas del gobierno (Deas, 1993). Ya en las décadas de 1940 y 1950, o incluso antes, se empezaron a abrir las primeras escuelas de economía en el país. En 1931 se fundó la Facultad de Ciencias Económicas y Jurídicas de la Universidad Javeriana, que en $\mathbf{1 9 6 4}$ dio origen a la actual Facultad de Ciencias Económicas. En 1945apareció el Instituto de ciencias económicas de la Universidad Nacional de Colombia, primer paso para la creación de la Facultad de Ciencias Económicas en 192. Así, consecutivamente, aparecieron la Facultad de Economía de la Universidad de los Andes en 1948, en la Universidad Jorge Tadeo Lozano en 1955 y en la Universidad del Rosario en 1960. A la vez que se empezó a incrementar la demanda de economistas para cargos públicos y privados.

Es importante tener en cuenta que fue en los años 1950 cuando el país introdujo de manera sistemática la planificación económica, lo que se reflejó en la creación del Departamento Administrativo Nacional de Estadística (Dane), en 1951, y del Departamento Nacional de Planeación (DNP). Así mismo, en 1960 se fundó Fedesarrollo, "una fundación privada donde participan los más importantes representantes del mundo empresarial y financiero, lo que dará un vuelco considerable a la investigación económica en el país y logrará imprimir una orientación neoclásica tanto a los estudios como a la enseñanza” (Bejarano, 1999).

El desarrollo de la economía colombiana -la profesión y el marco teórico en el que se inscribe-, no ha estado aislado de las condiciones internacionales. Un elemento de gran importancia para el desarrollo de la economía después de la segunda guerra mundial, esto es, de la economía como discurso, como práctica y como institución, o sea, como episteme de poder y conocimiento, es la demanda de las agencias internacionales de crédito, instituciones que requerían de análisis precisos de las variables macroeconómicas que el gobierno nacional debía estar en condiciones de conocer y negociar. Así mismo, está la proliferación de misiones extranjeras que entre 1930 y 1980 hicieron estudios y diagnósticos detallados de la economía colombiana, proveyendo marcos teóricos y elementos muy concretos de interpretación (Bejarano, 1999). Lo anterior supone el sometimiento a criterios de desempeño fijados por gobiernos extranjeros y entes multilaterales, a la vez que implica tener la capacidad de 


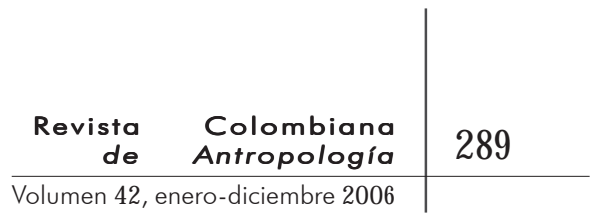

controlar los efectos políticos internos de los acuerdos internacionales.

Paralelamente hay hechos prácticos de la economía nacional y mundial que ayudan a entender la fuerza que tomó la ciencia económica hacia finales del siglo veinte. Primero, la crisis mundial que se desató en 1970; segundo, la crisis de deuda externa en la década de 1980; y, por último, la apertura económica en los años 1990. Estas tres situaciones son ejemplo palpable de los motivos que hicieron necesaria la participación de profesionales con conocimientos técnicos y capaces de interpretar los cambios mundiales y nacionales.

Sin embargo, si bien es cierto que la economía se ha convertido en una disciplina con gran poder debido a la complejidad creciente de las relaciones humanas, el hecho que los economistas no hayan permanecido en cargos puramente técnicos y se hayan desplazado a los altos niveles del gobierno está asociado a los significados ceremoniales que revisten a la condición de experto y a la creencia de que las cuestiones económicas tienen mayor importancia que ninguna otra para los gobiernos y para las relaciones internacionales. Lo que ha llevado a los economistas a convertirse en instrumentos de legitimación política. Como afirman Markoff y Montecinos,

la creencia de que las cuestiones económicas son centrales para la acción de los gobiernos y para las relaciones internacionales ha convertido el despliegue de ministros con Ph.D. en un nuevo instrumento de legitimación política. Esta creencia ha hecho que el lenguaje profesional de los economistas se convierta en una lingua franca política y ha estimulado a que los contactos y los valores profesionales transnacionales se conviertan en un contexto significativo para la adopción de decisiones políticas nacionales (Markoff y Montecinos, 1994: 6).

\section{"Primero mi primaria": acceso a la educación y distribución del ingreso}

T L ENFOQUE DE ESTE DOCUMENTO NO EXPLICA EL FENÓMENO DEL PODER $\sqcup$ a partir de diferencias socioeconómicas. Sin embargo, es inevitable que estas diferencias estén implícitas en buena parte de las prácticas que construyen el círculo de economistas del poder. 


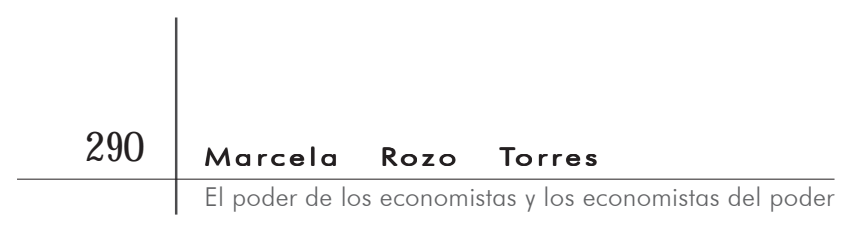

De manera que, sin necesidad de centrarnos en esto, podemos empezar la explicación de la conformación de este círculo de poder por lo más evidente: por las diferencias socioeconómicas que se reflejan en las diferencias de calidad en la educación y en el reducido acceso a la educación superior. Como lo afirma uno de los economistas entrevistados, ex alumno de la Universidad de los Andes, Ph.D de una de las más prestigiosas de Estados Unidos, ex ministro y actualmente dedicado a la banca e inversión:

Colombia es un país impresionante en concentración del ingreso y del poder, porque la gente muy rica es la gente muy educada, la correlación riqueza-educación es casi 1:1 Las mejores formaciones académicas, las mejores trayectorias, los mejores manejos de idiomas y muchas de esas cosas nacen de ahí, vienen de los colegios con los estándares más altos, es cero meritocracia, es oligarquía. Y ni siquiera es distribución de ingreso, es distribución de acceso a la universidad. El 90\% de las universidades de acá son un atraco a la gente, y pretender que vaya a estar la persona de la Unad en el Ministerio de Hacienda, pues no, eso no va a pasar nunca, y en cierta forma, dicho muy duro, gracias a dios no pasa nunca (ex ministro, actualmente dedicado al sector financiero. Entrevista realizada en abril de 2004).

De acuerdo con Bourdieu, el hecho de designar el grupo de estudio de acuerdo con una ocupación indica que la posición en las relaciones de producción gobierna las prácticas, en particular mediante el mecanismo que controla el acceso a posiciones, produciendo o seleccionando una clase particular de habitus. Sin embargo, los individuos agrupados en una clase que se establece respecto a un criterio particular, a un criterio explícito como la clase social, siempre traen consigo, además de las propiedades respecto a las que son clasificados, propiedades secundarias que pasan desapercibidas. Esto significa que una clase o la fracción de una clase no se define únicamente por su posición en las relaciones de producción, reconocida mediante indicadores como la ocupación, el ingreso o el nivel educativo, sino también por todo un conjunto de características subsidiarias que pueden funcionar, en la forma de requerimientos tácitos, como reales principios de selección o exclusión, sin estar formalmente establecidos en ningún momento (Bourdieu, 1979. 100).

Dando por hecho que el círculo de economistas del poder está determinado por la posición en las relaciones de producción, y tomando como eje central las prácticas y los requerimientos 


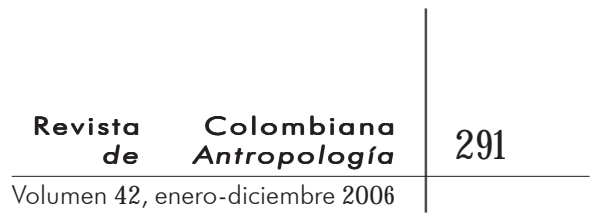

implícitos que los definen como grupo, empezaré por examinar cómo los mismos economistas explican la aparición y consolidación de este círculo de poder en Colombia.

\section{Consolidación de los economistas colombianos como círculo de poder}

OMO YA HEMOS VISTO, A LO LARGO DEL SIGLO VEINTE LA PRESENCIA DE $\bigcup$ economistas en el gobierno nacional aparece como indispensable. La consolidación de este grupo en el poder y su prestigio innegable van más allá de las necesidades puramente técnicas. Más allá de la necesidad de un conocimiento particular se empieza a tomar conciencia de que organismos como el DNP y el Banco de la República son un foco de poder y que, por eso mismo, constituyen un grupo que debe ser formado e institucionalizado. Podríamos atrevernos a pensar que esta institucionalización parte de la necesidad de definir el enfoque de estos organismos y, en consecuencia, de fijar los perfiles de quienes deben hacer parte.

En los cincuentas (sic) llega Currie con la misión del Banco Mundial. Al final de los cincuenta Lleras Camargo nombra en Planeación a Gutiérrez Castro, luego viene Valencia. Yo digo que es mucho Planeación y luego el Banco de la República los que forman la élite. A final de los sesenta yo creo que hay una conciencia grande de gente que sabe que ese grupo hay que formarlo e institucionalizarlo. En el Banco de la República gente como Ortega, un poco por la formación de esta facultad [la facultad de economía de la Universidad de los Andes]. La gente que tiene en cuenta la formación de esta facultad, la gente que está en Planeación que es toda el mismo grupo: Junguito, Perry, Urrutia, Ortega (alto miembro del gobierno central en su momento, actualmente dedicado a la academia. Entrevista realizada en marzo de 2004).

Así mismo, se tiene conciencia de la necesidad de que ese grupo se aleje de las riñas partidistas, en la medida que sean percibidos como una élite intelectual, lo que les permite argumentar neutralidad. De esa manera, se pueden asegurar que los cargos decisivos en la toma de decisiones de política económica estén en manos de economistas “idóneos", independientemente de lo que suceda en la arena política. 


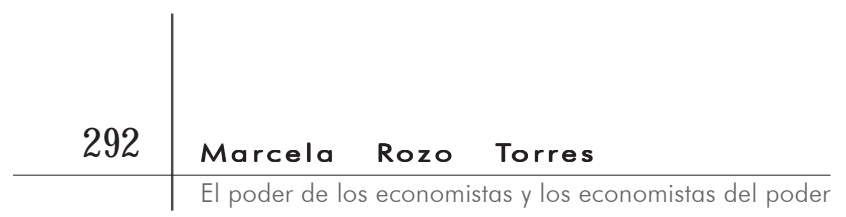

Surge un grupo suprapartidista (refiriéndose a los economistas) al cual, suba el gobierno que suba, nombran a ese grupo. En ese grupo puede haber tendencias más de derecha y más de izquierda, pero es un mismo grupo que se ve, en el que escriben las cosas, que se respetan y que son amigos. Y ese grupo surge con la gente que va y hace estudios en el exterior, Estados Unidos en particular se vuelve muy importante (alto miembro del gobierno central en su momento, actualmente dedicado a la academia. Entrevista realizada en marzo de 2004).

Si bien el ascenso de los economistas y, en particular, su incursión en el gobierno nacional empieza a ser visible desde mediados del siglo veinte, su consolidación como círculo de poder y su paso definitivo de profesionales técnicos a expertos se inicia con los "economistas jóvenes" en 1974, durante el gobierno de Alfonso López Michelsen (1974-1978), fortaleciéndose y haciéndose indiscutible con la crisis de la deuda en la década de 1980. Esta fue, sin duda, una gran oportunidad para que los economistas colombianos, y en general los latinoamericanos, elevaran su posición y adquirieran no sólo prestigio como profesionales, sino como hacedores de políticas públicas y como representantes ante el resto del mundo. "Su formación les permitió crear buenas relaciones con aquellos con quienes tenían que negociar la deuda. Sirviéndoles su habilidad para hablar inglés, los conocimientos técnicos en economía, las conexiones con la comunidad de economistas de Estados Unidos y la empatía con los discursos democráticos que adquirieron en Estados Unidos” (Dezalay y Garth, 2002: 82).

\footnotetext{
Después de la crisis de la deuda vino la presión de los organismos internacionales y de los prestamistas extranjeros de tener más economistas cercanos al gobierno. Esos organismos buscaban como interlocutores a los economistas, nuevamente buscaban personas que hablaran inglés y los economistas normalmente hablan más inglés que los abogados, y que hablaran de economía (miembro de la junta directiva del Banco de la República. Entrevista realizada en marzo de 2004).
}

El surgimiento y fortalecimiento de esta élite de economistas puede analizarse desde dos perspectivas. Por un lado, como círculo de poder dentro de la sociedad colombiana, forjándose y consolidándose mediante las instituciones en las que se forman académicamente, los estudios que adelantan en universidades internacionales, los círculos sociales a los que pertenecen y el 


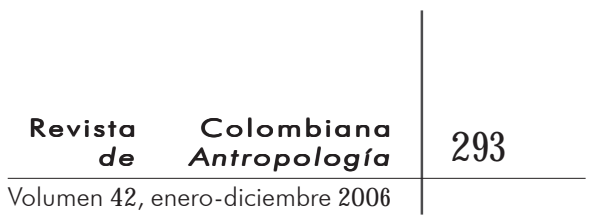

recorrido profesional. Y, por otra, es posible inscribirlos en un proceso global, en la formación de una élite internacional, una élite economista que busca promover y expresar un discurso económico particular.

Es claro que estas dos aproximaciones no se pueden entender como aisladas; por el contrario, son dos procesos que se retroalimentan y que se necesitan mutuamente para fortalecerse. Por ejemplo, para empezar a hacer parte de la élite internacional es necesario cumplir con los requisitos académicos y profesionales que se obtienen gracias al título nacional. Y a su vez la élite nacional utiliza los estudios en universidades extranjeras, el paso como profesores o investigadores en esas mismas universidades, y en organismos multilaterales, para afianzarse y legitimarse como un grupo de poder local.

El hecho de que ciertas universidades se conviertan en símbolos de la élite, en lugares prácticamente obligados -aunque evidentemente existan excepciones- para acceder al círculo del poder, puede entenderse por la apropiación que presupone el consumo de los bienes, en este caso de la educación. Esto significa que el mismo consumidor, mediante un trabajo de identificación y decodificación, ayuda a producir el producto que consume. Aun cuando los bienes tengan unas características técnicas dadas por el proceso de producción, los consumidores no perciben necesariamente los mismos atributos. El consumo tiene un elemento subjetivo en la forma en la que el consumidor se apropia de los bienes, en la significación y los usos sociales que se le den. De manera que existen "esquemas de percepción, apreciación y acción, que no se pueden limitar a percepciones individuales, y que nos permiten encontrar la relación entre gustos que necesariamente varían de acuerdo a las condiciones sociales y económicas de producción” (Bourdieu, 1979. 97-99). De esta forma, los niveles académicos de cada institución podrían ser identificados como las características técnicas del producto, pero independientemente de estos, el hecho de que la élite se reproduzca casi sistemáticamente en las mismas universidades, nacionales e internacionales, puede ser explicado por la significación y prestigio que la élite misma se encarga de adjudicarle a esas instituciones, elementos que ellos mismos se van a encargar de mantener al utilizar estas universidades como su lugar de reproducción. 


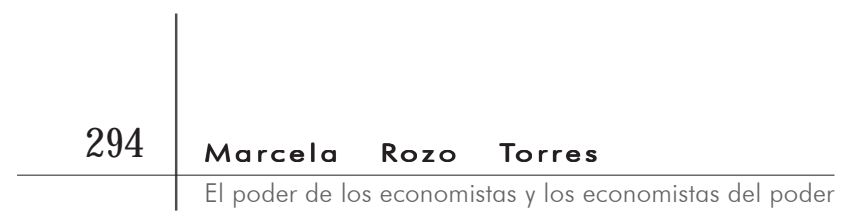

El poder de la Facultad de Economía de la Universidad de los Andes

F N CUANTO A LA CONSTRUCCiÓN DE LA ÉLITE NACIONAL, EN COLOMBIA EL $\sqcup$ carácter político e ideológico de las universidades puede ser fácilmente ejemplificado con el contraste que existe entre la Universidad Nacional y la Universidad de los Andes, dos universidades reconocidas por sus elevados niveles académicos en la enseñanza de la economía, pero cuyos egresados se han venido ubicando en lugares muy diferentes a lo largo de las últimas décadas. Mientras que la Facultad de Economía de la Universidad Nacional es vista comúnmente como una institución orientada al análisis teórico y a la producción de discursos heterodoxos, aunque cada vez menos, la Universidad de los Andes se presenta como apolítica, técnica y abierta a la internacionalización. Lo anterior tiene como resultado que los uniandinos aparezcan como los más "aptos" tanto para los cargos estatales que requieren de tecnicidad y neutralidad, como para los estudios de posgrado y doctorado en el exterior, que les permiten continuar el camino hacia el poder (Palacios, 1999). Esto, reforzado por el hecho de que la universidad privada funciona no sólo como un filtro gracias a sus elevadas matrículas, sino como una forma de ingresar a las redes de poder, ganar prestigio y acumular capital cultural, social y económico.

Según Ahumada, fue a partir del gobierno de Virgilio Barco (1986-1990) que la Universidad de los Andes se consolidó como la principal fuente de cuadros políticos para los gobiernos. Al ser una de las universidades más elitistas del país, ha suministrado muchos candidatos para ocupar altos cargos públicos y privados (Ahumada, 1996: 150), a tal punto que entre 1958 y 2000, de sesenta y dos ministros de Hacienda, gerentes del Banco de la República y directores del DNP, treinta y dos han sido uniandinos (Palacios, 2001). A los que podemos sumar los dos ministros de Hacienda que ha tenido la administración de Álvaro Uribe (2002-2006; 2007-) (Roberto Junguito y Alberto Carrasquilla), los tres últimos directores del DNP correspondientes a los gobiernos de Andrés Pastrana (1998-2002) y Álvaro Uribe (Juan Carlos Echeverry, Santiago Montenegro y Carolina Rentería), los dos últimos subdirectores de esa misma institución (José Leibovich y Mauricio Santamaría) y tres de los miembros de la actual junta directiva del Banco de la República (Carlos Gustavo Cano, Fernando Tenjo y Leonardo Villar). 


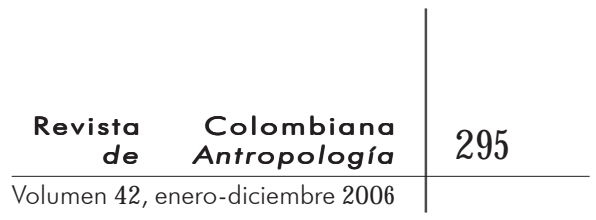

Esto en cuanto al tránsito de la Universidad de los Andes hacia el gobierno, pero del gobierno hacia esta universidad también existe un movimiento constante. Por ejemplo, el ex decano de la Facultad de Economía (Juan Carlos Echeverry) actualmente docente de esta universidad; el director del Cede, centro de investigación de esa facultad (Fabio Sánchez); y el actual decano (Alejandro Gaviria), han sido director del DNP durante el gobierno de Andrés Pastrana y subdirectores en los gobiernos de Ernesto Samper (1994-1998) y Álvaro Uribe, respectivamente, todos ex alumnos de economía de la Universidad de los Andes, ya sea de pregrado o de posgrado. Lo mismo sucede con los cursos y seminarios que normalmente dictan el ministro de Hacienda (Alberto Carrasquilla), por lo menos dos de los miembros de la junta directiva del Banco de la República (Sergio Clavijo y Leonardo Villar) y un ex ministro de Minas y Energía (Luis Carlos Valenzuela) ${ }^{2}$.

El predominio de ex alumnos 2. Hasta 2004.

de la Universidad de los Andes en altos cargos de las instituciones gubernamentales es explicado en algunos casos, simplemente, por la mejor calidad de su educación respecto a otras universidades, convirtiéndolos en los economistas mejor preparados y, por tanto, en los más idóneos para cargos de tan alta responsabilidad. Como afirma uno de los economistas entrevistados, egresado de la Universidad Nacional:

(La Universidad de los Andes cuenta con) mejor formación académica, más actualizada y técnica, mayor preocupación con temas relevantes para las decisiones de política económica (asesor económico de varios gobiernos, autor de textos de economía y actual miembro de un organismo multilateral. Entrevista realizada en abril de 2004).

Así mismo, podría decirse que la superioridad que se adjudica a los economistas uniandinos se debe tanto a la calidad de la docencia y al espíritu investigativo de la institución, como a la selección de sus alumnos:

Yo creo que tiene mucho que ver con la docencia. Por dos cosas. Uno es el esquema de investigación, aquí la gente se la forma más orientada hacia que investigue, cree algo de conocimiento. Segundo, la gente que viene acá, viene de los mejores colegios y eso genera una selección muy grande, porque usted coge los mejores chinos, no 


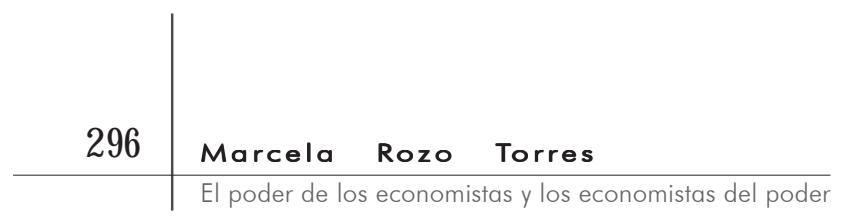

necesariamente los más inteligentes. Lo más importante de un niño (y de las familias) es su actitud intelectual, es que sea lector, que sea inquieto, que busque hacerse preguntas. Es una persona que en general, más que en el colegio, en su casa misma, la actitud espiritual, el ambiente espiritual de su casa hace un ambiente inquisitivo, es un ambiente en el que se valora leer, en el que se valora preguntarse, en el que se valora criticar, criticar inteligentemente (alto miembro del gobierno central en su momento, actualmente dedicado a la academia. Entrevista realizada en marzo de 2004).

En este caso sería indispensable preguntarse acerca de las causas de los diferentes niveles de educación escolar, así como de la "capacidad inquisitiva" de los hogares a los que alude el entrevistado. Quienes se presentan a la Universidad de los Andes vienen en su gran mayoría de colegios privados, eso significa que pertenecen a familias con una capacidad económica muy superior a la mayoría de familias del país, y que por esto mismo tienen una educación básica de mejor calidad. De manera que es muy difícil referirse a la calidad de los alumnos sin relacionarla directamente con su capacidad socioeconómica. Sin embargo, si dejamos el carácter socioeconómico de lado y nos centramos en el argumento del nivel de educación, la docencia y la selección de los alumnos, valdría la pena preguntarse, ¿por qué son los egresados de la Universidad de los Andes los que conforman este círculo de poder?

El hecho de que la educación uniandina facilite el acceso al poder probablemente sí está relacionado con la calidad de la educación, pero la pregunta es por qué sobresale sobre universidades como la Nacional, que tradicionalmente ha sido reconocida por su calidad académica, por su orientación hacia la investigación y por tener procesos de selección de los estudiantes mucho más sofisticados, en cuanto a capacidad académica, que los de la Universidad de los Andes. Así mismo, valdría la pena preguntarse por los economistas de la Universidad del Rosario y la Universidad Javeriana, dos instituciones que tienen tanta o más trayectoria en la enseñanza de la economía, que en algunos momentos de la historia han ocupado cuadros importantes en el gobierno y en entidades prestigiosas, pero que en las últimas décadas han ido cediendo estos cargos a los egresados de la Universidad de los Andes.

Algunos entrevistados explican este interrogante por factores como el enfoque más matemático de la educación uniandina 


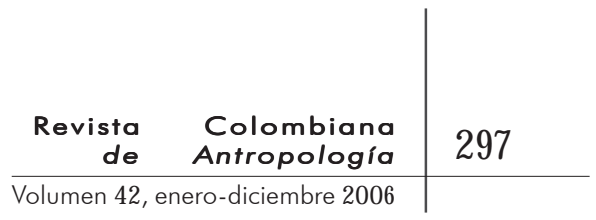

y la exigencia del inglés. Esto sitúa su educación en una posición aparentemente más cercana a la utilizada en las universidades estadounidenses, dándole un enfoque que está más acorde con el de la élite internacional. Como afirman Dezalay y Garth, la ortodoxia latinoamericana de finales del siglo veinte y comienzos del veintiuno ha estado representada por el saber económico y las instituciones que lo reproducen. En ese contexto, la matematización de este saber aparece como la herramienta analítica que le da el aire de neutralidad y verdad científica que tienen, por definición, todas las ortodoxias. Esto ha hecho que se promueva un proceso de competencia en el que las matemáticas suministran la medida para determinar las jerarquías académicas y la credibilidad científica, convirtiendo esta herramienta en una estrategia de valoración simbólica bastante útil para afirmar la legitimidad de un nuevo campo de conocimiento, el de la ciencia económica (Dezalay y Garth, 2002: 122).

\begin{abstract}
Hay un énfasis mayor en modelos matemáticos en los Andes que es más cercano al esquema de enseñanza de los Estados Unidos y de Inglaterra, y eso también facilita que se vayan. Los dos puntos críticos tradicionalmente han sido el inglés y las matemáticas, pero creo que en las matemáticas la Nacional ha mejorado muchísimo. Entonces la posibilidad de que salgan economistas de la Nacional con buena formación matemática y con posibilidad de ir a estudiar al exterior cada vez es mayor. Ya lo que les falta es el inglés (miembro de la junta directiva del Banco de la República. Entrevista realizada en marzo de 2004).
\end{abstract}

Por su parte, el inglés puede ser visto como un requisito puramente técnico, pero que a su vez es un ejemplo de las diferentes oportunidades que representa pertenecer a determinada clase social, de las diferencias en la calidad de la educación escolar y de las posibilidades que se ha tenido de aprenderlo en un país angloparlante; además de ser un elemento indispensable para tener acceso a los estudios en el exterior.

Podría afirmarse que para estudiar en las universidades más prestigiosas del exterior, que normalmente son estadounidenses, existen dos posibilidades: poseer el dinero necesario para el estudio y la manutención, o conseguir una beca que cubra estos gastos o parte de ellos. Pero para tener acceso a estas becas es necesario haber sido aceptado en alguna universidad y esto significa, entre otras cosas, tener una educación similar a la de 


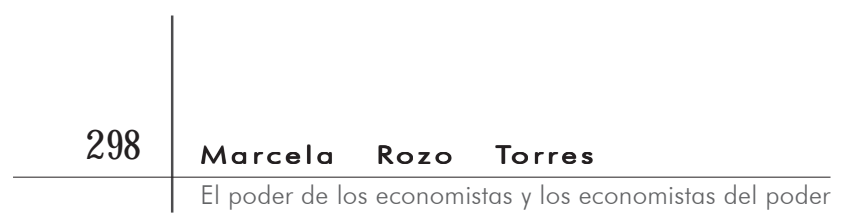

esas universidades, tener las cartas de recomendación apropiadas y dominar el idioma.

El requisito fundamental para acceder a esas becas es que el estudiante tenga ingreso o aceptación ya en una universidad de primer nivel del exterior, y ese requisito es difícil que lo cumplan estudiantes que, primero no tengan inglés y normalmente estudiantes de fuera de los Andes. Eso está cambiando, ya los últimos años se han ido varios de fuera de Bogotá, se han ido del Rosario, la Javeriana. Pero el obstáculo principal era que no los recibían en el exterior y eso tenía que ver con el inglés y con el círculo ese que se forma entre los profesores de los Andes y los sitios en los que ellos mismos han estudiado afuera. Entonces ese vínculo hace que después, ya cuando están en altos cargos de política o en investigación, en sitios como Fedesarrollo, termine un vínculo indirecto con los Andes muy cercano, pero no creo que surja de que tenga que ser de los Andes o de razones de roscas personales (miembro de la junta directiva del Banco de la República. Entrevista realizada en marzo de 2004).

Como vemos, la mayor facilidad para acceder a las universidades del exterior se ha ido retroalimentando constantemente gracias a otros factores, como al círculo de influencias que se forma con los uniandinos que vuelven de sus maestrías y doctorados a ocupar cargos en esta misma universidad, en lugares de alta influencia dentro del gobierno o en prestigiosas entidades privadas, convirtiéndose así en las principales piezas de la élite.

Cuando los colombianos llegan de afuera de hacer doctorados o maestrías, tienen mucha más facilidad de entrar en esos grupos de Fedesarrollo o de alta política económica, que no la tiene una persona que no ha podio estudiar en el exterior. El vínculo que hay entre haber estado en los Andes e irse al exterior es lo que yo creo que marca la posibilidad de influir tanto en la política y estar en los centros de investigación. Ahora, eso crea su propio círculo vicioso, o virtuoso desde el punto de vista de los Andes. En la medida en que las universidades del exterior empiezan a recibir uniandinos y les va bien, entonces los profesores de las universidades empiezan a buscar uniandinos. Cuando llega una persona de una universidad que ellos no conocen, no saben a que atenerse y prefieren el conocido, en el sentido de la universidad conocida. A veces ya conocen el profesor porque es la persona que estudió allá y llegó aquí y volvió a vincularse a los Andes y ese es el que recomienda, y entonces se empieza a generar un vínculo estrecho entre los Andes y las universidades del exterior (miembro de la junta directiva del Banco de la República. Entrevista realizada en marzo de 2004). 


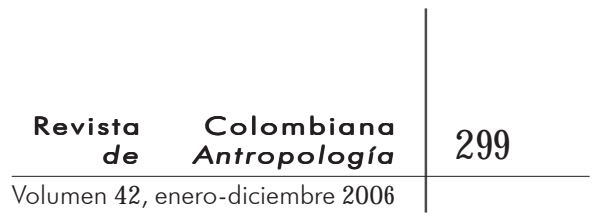

Así, ellos mismos se encargan de seguir reproduciendo las ventajas con las que se iniciaron en el juego. Que los ex alumnos de los Andes hayan tenido la oportunidad de estudiar en el exterior y, además, hayan logrado un buen desempeño, es lo que en buena medida le facilita a las generaciones siguientes tener acceso a esas instituciones. Esto va a ser reforzado por quienes vuelven de sus maestrías y doctorados a ejercer como catedráticos en su antigua universidad, teniendo la oportunidad de recomendar a sus alumnos en las universidades extranjeras en las que estudiaron.

Como veíamos antes, los ex alumnos de los Andes no sólo van a regresar a ejercer en el área académica, sino como profesionales en la rama pública, en los centros de investigación y en la empresa privada; y ya estando en esos lugares, es normal que sigan buscando alumnos o ex alumnos de su universidad, lo que va a permitir que el círculo de poder se siga recreando en sus aulas. Uno de los entrevistados ejemplifica de la siguiente manera, no sólo la forma en la que fue inicialmente reclutado, sino cómo él mismo se encarga de reproducirla:

Eso es una cosa que tiene mucho que ver con señales del mercado laboral que no son exclusivas nuestras [de la Universidad de los Andes]. Una recomendación es muy importante. Usted tiene dos personas en el mismo mercado, pero si una viene recomendada o usted la conoce, que fue lo que me pasó a mí. ¿Yo por qué entré al Banco de la República? Porque un amigo mío, que había sido monitor mío, que estaba allá en el Banco de la República, me recomendó. Y muchas veces los salones de clases de los Andes son el sitio donde se retroalimenta eso.

Ortega [Juan Ricardo] estaba aquí [en la Universidad de los Andes], yo me lo llevé para Planeación, en Planeación estuvo un año, después yo lo mandé a presidencia, en presidencia estuvo otro año y ahí lo cogió [Roberto] Junguito y ahora está de viceministro de Comercio Exterior. Yo no lo he pensado demasiado, sé que funciona. Hoy en día los niños ya toman concientemente esa decisión cuando entran a esta universidad (alto miembro del gobierno central en su momento, actualmente dedicado a la academia. Entrevista realizada en marzo de 2004).

Lo anterior no significa que la selección no se deba a que son los mejores dentro del medio en el que se encuentran. Lo interesante es cómo se van reclutando en el mismo círculo, cómo pertenecer a cierta institución va a permitirles tener un acceso 


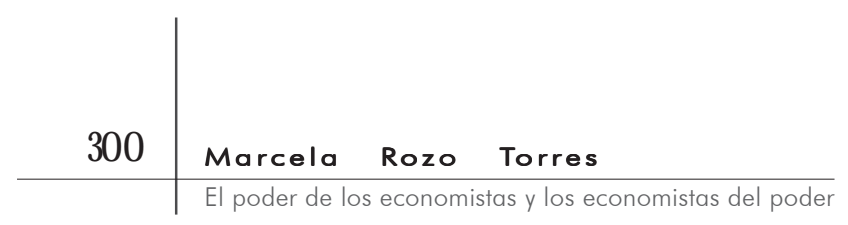

mucho más directo a los espacios de poder, que a quienes pueden ser igualmente buenos pero pertenecen a otra institución y a otro círculo de influencias.

Este proceso de selección en las aulas de clase no implica que mantener el poder en la Universidad de los Andes sea una decisión plenamente consciente, sino que, de una u otra manera, se van elaborando los argumentos que justifican que sean ellos y no otros los más apropiados para estar en cargos con alto grado de influencia. De hecho, los entrevistados no explican su acceso al poder por la influencia o la acumulación de capital social que puede significar haber estudiado en los Andes, sino por factores como su mejor preparación y los estudios en el exterior. Como sostiene uno de ellos:

Yo he pasado por muchos puestos públicos y muchos puestos privados, y lo último que me importa es si viene de los Andes o no. No hay unidad, yo jamás he pisado una cosa de ex alumnos de los Andes, en mi vida he estado en una reunión de la gente con la que me gradué, todos con un poder violento, yo me gradué con [Alberto] Carrasquilla, Leonardo [Villar], si hago la lista, todos, y con cero unión (ex ministro, actualmente dedicado al sector financiero. Entrevista realizada en abril de 2004).

Sin embargo, a pesar de negar la influencia que puede tener haberse graduado de esa universidad, la falta de unidad entre sus miembros y de afirmar que es un proceso que no se reproduce conscientemente, funciona en parte por la necesidad que se tiene de contratar y mantenerse cerca de aquellos que tienen su misma educación, de quienes han tenido un recorrido similar y que probablemente van a tener una misma manera de entender y enfocar los asuntos que enfrentan. En cuanto a la contratación de uniandinos, este mismo entrevistado dice:

Claro que es muy evidente, porque cuando usted tiene que tomar decisiones de política y ese tipo de cosas, o en cualquier trabajo, uno comienza a hablar lenguajes muy similares. Evidentemente yo me voy a entender con usted mucho más fácilmente que con la persona de la UIS de Santander. Es que son formaciones, los sobreentendidos, los chistes. Eso sí genera algo que es bastante normal, bastante natural (ex ministro, actualmente dedicado al sector financiero. Entrevista realizada en abril de 2004). 


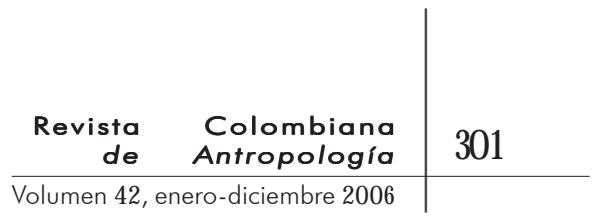

El caso de la Facultad de Economía de la Universidad de los Andes es, simplemente, una manera de ejemplificar el problema, un punto de coincidencia que se encuentra en la mayoría de altos cargos de poder económico y nos permite partir de un lugar común para dilucidar las prácticas que forman a esos individuos y, por tanto, las que marcan el proceso de ascenso al poder. Es necesario tener en cuenta que este poder ha sido sustentado en otros momentos por otras instituciones, normalmente obedeciendo a las inclinaciones ideológicas de los gobiernos nacionales y a funcionarios muy poderosos que a la hora de formar un equipo eligen a sus iguales. No obstante, vemos también cómo en las últimas décadas el poder se ha ido concentrando cada vez más en la facultad de economía de Universidad de los Andes, creándose así, como se afirma en una de las entrevistas, "un círculo vicioso o virtuoso, desde el punto de vista que se mire". Este círculo tiene la capacidad de mostrarnos los momentos y los espacios en los que se va creando y recreando la élite nacional y, a su vez, cómo se hila esta con la élite internacional.

Es necesario aclarar de nuevo que el punto fundamental de este análisis son las prácticas que llevan a un individuo a pertenecer o no a los círculos de poder de la economía, prácticas que se relacionan directamente con la acumulación de capital en el sentido utilizado por Bourdieu, es decir, de recursos que reportan beneficios y dan poder a los actores sociales. Estos recursos son principalmente el capital económico -dinero-, cultural -conocimiento, grados académicos, credenciales profesionales-, social -conexiones- y simbólico -prestigio-. De manera que si bien lo que diferencia a los economistas de las élites tradicionales es que se apoyan relativamente "menos en el capital familiar y más en sus propios conocimientos especializados, así como en la red cosmopolita construida de manera concurrente con la adquisición de sus conocimientos y posterior desarrollo de sus carreras", también es cierto que la mayoría de economistas del poder tienen muy buenas conexiones y cuentan con abolengos más o menos cercanos a la élite (Dezalay y Garth, 2002: ๔).

Creo que es la universidad [la de los Andes] que ha producido los economistas con mejor formación académica, que además provienen en su mayoría de familias pudientes y en algunos casos muy bien conectadas (asesor económico de varios gobiernos, autor de textos de economía y actual miembro de un organismo multilateral. Entrevista realizada en abril de 2004). 


\section{Ph.D: la ratificación de una ideología internacional}

I OS ESTUDIOS DE MAESTRÍA Y DOCTORADO EN UNIVERSIDADES DEL EX$\downarrow$ tranjero, el paso como profesores visitantes en esas instituciones y las publicaciones en revistas internacionales permiten que en cierta medida la élite nacional y la internacional se unifiquen y fortalezcan.

Para los economistas colombianos, las estrategias internacionales aluden a cómo se busca utilizar el capital extranjero -recursos, grados académicos, contactos, legitimidad, técnicas y conocimientos especializados- para erigir su poder local (Dezalay y Garth, 2002: 30). Y si bien lo más probable es que antes de sus estudios estos sujetos ya cuenten con cierto grado de acumulación de capital, las universidades dentro y, aún más, fuera de sus países de origen, les permiten seguir acumulando diferentes capitales -económico, cultural y social-indispensables para ser parte de los cuadros económicos más altos. Así mismo, aun cuando en el país existen universidades que les ayudan a tomar el camino adecuado hacia el poder, el paso por las universidades extranjeras es el más visible y el de mayor peso a la hora de justificar sus posiciones de poder.

Así mismo, y en parte gracias al prestigio y la credibilidad que otorga un título internacional, los estudios en el exterior se han convertido en una condición, especialmente cuando se trata de acceder a altos cargos estatales. Que los gobiernos nacionales tengan la necesidad de negociar préstamos con bancos privados, públicos y entes multilaterales, así como la necesidad de someterse a los criterios de desempeño fijado por estos, ha hecho indispensable la presencia de funcionarios que hablen el mismo lenguaje de sus interlocutores y comulguen con su discurso; de manera que un Ph.D que probablemente se formó en las mismas aulas que aquel con el que debe negociar se convierte en una herramienta perfecta de legitimación y de comunicación.

No es solamente el inglés, va mucho más allá del inglés. Es hablar un poco el mismo idioma en el sentido profesional. Una persona con formación de economista de una universidad americana o inglesa, como es buena parte de los funcionarios del Fondo Monetario, tiene una cierta lógica en la forma como plantean una recomendación. Ellos buscan comprensiblemente que la contraparte en Colombia 


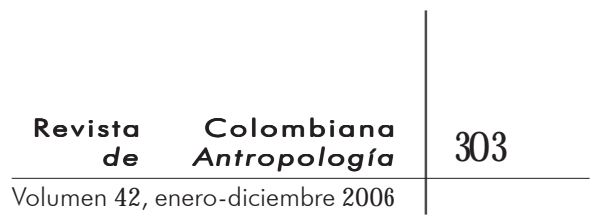

les entienda esa lógica, que entienda lo suficiente de economía para que cuando ellos hablen sepan de que están hablando, sepan por qué en un momento dado una recomendación que pueda parecer contraintuitiva para una persona que no sea economista, el economista le entiende la lógica que está detrás de eso. En ese sentido hay un problema de comunicación que va más allá del idioma inglés (miembro de la junta directiva del Banco de la República. Entrevista realizada en marzo de 2004).

En este contexto, los economistas que se desempeñan en los gobiernos nacionales aparecen como el ejemplo adecuado de lo que se define como tecnócrata, como profesionales "provistos de maestrías y doctorados en economía de Harvard, Yale, MIT y otras universidades de la élite en Estados Unidos", que "regresan a casa a atacar rancios y desacreditados conceptos económicos y a presionar por que se adopten soluciones de mercado. Los unifica una fe firme en la importancia de los números y una visión del mundo que se extiende más allá de los límites de sus países" (Ahumada, 1996: 141). Esto hace explícito el vínculo de un grupo de poder nacional con una élite más global, con un grupo en cierta medida homogéneo que comparte una misma visión del mundo y que, por esto mismo, orienta sus discusiones y soluciones de una misma manera, la manera del mercado.

\section{Trayectoria laboral: \\ el poder de la política económica}

$\int$ I BIEN EL PASO POR UNIVERSIDADES EXTRANJERAS PRESTIGIOSAS ES PRÁC$\int$ ticamente un paso obligado para el ascenso al poder, estos títulos no son suficientes en sí mismos. El inicio del recorrido está en la academia, pero se fortalece con elementos como la rotación por cargos en ciertas entidades y la acumulación del capital social necesario para acceder a estos cargos.

En las entrevistas se identifica una dificultad creciente para ascender en el gobierno, en parte debido al aumento de la competencia gracias a la mayor facilidad que existe hoy en día para estudiar en el exterior, y en la necesidad de poseer ciertas habilidades para acceder a los cargos públicos y tener un buen desempeño en ellos. 


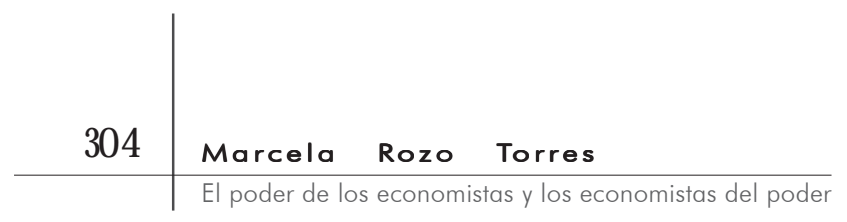

Ya todos los años hay una cantidad de gente que vuelve (...) ya no es tan garantizado que el que pudo irse puede llegar acá a cargos altos, hoy uno empieza a ver gente muy calificada dentro del Banco o dentro del gobierno y en el sector privado que simplemente llegan y les toca competir en condiciones difíciles. Tanto que hoy ya hay mucha gente que prefiere no venirse (miembro de la junta directiva del Banco de la República. Entrevista realizada en marzo de 2004).

El acceso al círculo del poder requiere de un recorrido posterior a la academia, con unas prácticas específicas que permitan seguir acumulando el capital necesario para pertenecer a la élite. En el discurso de estos personajes, este capital puede estar representado en cargos que les permitan demostrar sus capacidades académicas, de liderazgo y de toma de decisiones.

La legitimación y el prestigio de estos profesionales se fortalece con el paso por ciertas entidades como organismos multilaterales, centros de investigación, entidades públicas como el Banco de la República, el Ministerio de Hacienda y Crédito Público y el Departamento Nacional de Planeación, el paso por la academia como catedráticos, y, en general, un recorrido y una rotación por entidades que cuenten con cierto prestigio nacional e internacional. Así mismo, cuando nos referimos a cargos en el sector público entra a contar la necesidad de tener un apoyo político lo suficientemente fuerte como para llevar a cabo las decisiones que se tomen.

No es sólo meritocracia. Además se necesita contar con apoyo político para sacar adelante decisiones difíciles y para decirle no al presidente y a los otros ministros cuando es necesario (asesor económico de varios gobiernos, autor de textos de economía y actual miembro de un organismo multilateral. Entrevista realizada en abril de 2004).

Este movimiento de los economistas entre diferentes entidades de carácter público y privado se debe, en parte, al hecho de que las élites han procurado sustituir la compleja evaluación de la efectividad de las políticas públicas por la evaluación del ceremonial que los rodea. De manera que la efectividad de los economistas termina confundiéndose con criterios externos de reputación, es decir, con criterios que no responden necesariamente a su desempeño como hacedores de políticas, sino asociados con sus calificaciones -credenciales profesionales, doctorados en universidades prestigiosas- $y$, por otra parte, con 


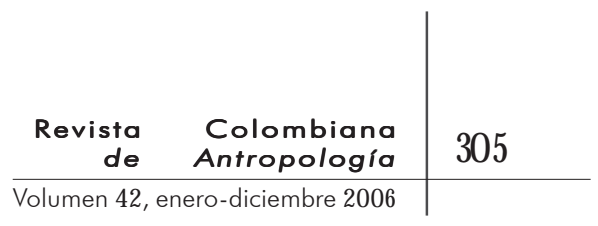

sus esfuerzos por seguir los "estándares aceptados de práctica profesional y procedimientos ritualmente definidos" (Markoff y Montecinos, 1994: 22).

Una manera de acercase al recorrido y las prácticas que generalmente comparten quienes acceden a las altas esferas en la economía es tomar como ejemplo los cargos directivos del Banco de la Republica, entidad reconocida por poseer economistas con alta formación y que, a pesar de ser una entidad pública, su carácter independiente permite que se identifiquen como "neutros" o "apolíticos". Como afirma Ahumada (1996), los miembros de la junta directiva del Banco de la República pueden ser un ejemplo perfecto del papel que desempeña la élite de tecnócratas. El hecho de que en la Constitución de 1991se le haya otorgado autonomía "administrativa, patrimonial y técnica" a esta entidad abrió el espacio para que su funcionamiento respondiera a un régimen legal propio a la vez que "amplió sus funciones de manera considerable, al convertirlo en autoridad monetaria, cambiaria y crediticia del país". Así mismo, de la autonomía otorgada en 1991se desprendieron nuevas funciones como, por ejemplo, ser el "representante del Estado ante los distintos organismos financieros internacionales y el canal de comunicación con ellos" (Ahumada, 1996: 150).

Como se afirma en un artículo de Portafolio publicado en abril de 2004, y que en cierta medida refleja la opinión pública, los puestos en la junta directiva del Banco de la República

son muy apetecidos no sólo por su nivel de ingreso sino por la importancia que tienen (...) La gerencia del Banco es, sin duda, uno de los cargos más importantes del país. El gerente del Emisor no sólo ejerce como miembro de la Junta Directiva, y es el representante legal del Banco, sino que tiene un estatus especial que encarna poder y respeto. Sus opiniones tienen tanta trascendencia y llegan a influir tanto en la vida del país casi como al mismo nivel que un Ministro de Hacienda, funcionario que, muchos consideran, en Colombia tiene un poder omnímodo (Portafolio, 2004).

Partiendo del prestigio que significa para un economista pertenecer a esta institución, tomaremos como ejemplo a los dos gerentes que ha tenido desde su independencia en 1991(Miguel Urrutia y José Darío Uribe), a los actuales miembros de la junta directiva (Alberto Carrasquilla, Carlos Gustavo Cano, Juan José Echavarría, 


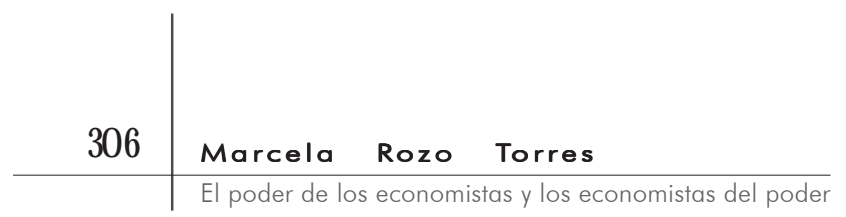

Luis Mario Laserna, Fernando Tenjo y Leonardo Villar), a tres de los codirectores que se han retirado en los últimos años (Carlos Caballero Argáez, Sergio Clavijo y Salomón Kalmanovitz) y a un ministro de Hacienda del primer gobierno del presidente Uribe: Roberto Junguito Bonnet.

En la tabla 1(página 313) se muestran algunos de los cargos más significativos que han ocupado esos personajes. Esto nos permite ver las prácticas y los lugares que comparten, que en cierta medida se pueden entender como requisitos necesarios para acceder a uno de los cargos más poderosos en los cuadros económicos. El recorrido está marcado inicialmente por su formación académica. De los doce miembros considerados, ocho son ex alumnos de la Universidad de los Andes, seis graduados de economía y uno (Carlos Caballero Argáez) de ingeniería civil. Tres cursaron sus estudios de pregrado fuera del país (Salomón Kalmanovitz, Juan Mario Laserna y Miguel Urrutia) y sólo Juan José Echavarría y José Darío Uribe son egresados de universidades colombianas diferentes a los Andes. A esto podríamos sumarle el hecho de

3 Carlos Caballero Argáez, Carlos Gustavo Cano, Sergio Claviio, María Mercedes Cuéllar, Juan José Echavarría, Luis Bernardo Flórez, Hernando José Gómez Restrepo, Antonio Hernández Gamarra, Rudolf Hommes, Roberto Junguito, Salomón Kalmanovitz, Juan Mario Laserna, Néstor Humberto Martínez, Óscar Marulanda Gómez, Francisco Ortega, Carlos Ossa Escobar, José Darío Uribe, Miguel Urrutia y Leonardo Villar. que, de las dieciocho personas ${ }^{3}$ que han ocupado el cargo de codirectores en la junta directiva del Banco de la República desde su independencia en 1991, es decir, excluyendo a los ministros de Hacienda, diez han sido economistas de la Universidad de los Andes, los que mencionamos en la tabla anterior: Carlos Gustavo Cano, Sergio Clavijo, María Mercedes Cuellar, Roberto Junguito, Fernando Tenjo, José Darío Uribe y Leonardo Villar; sumados a Hernando José Gómez Restrepo, Francisco Ortega y Carlos Ossa Escobar.

En cuanto a los estudios más avanzados, como maestrías y doctorados, nueve de ellos obtuvieron títulos de prestigiosas universidades estadounidenses. Dos de los miembros de la junta, Juan José Echavarría y Leonardo Villar, cursaron sus estudios en Gran Bretaña, y sólo Fernando Tenjo obtuvo su título en un país diferente a los mencionados.

Seguido de esto, en el recorrido por el mercado laboral se encuentran múltiples coincidencias. En cuanto a los cargos en el gobierno, tres de los miembros, Carlos Caballero, Carlos Gustavo Cano y Miguel Urrutia, han estado a cargo de algún ministerio 


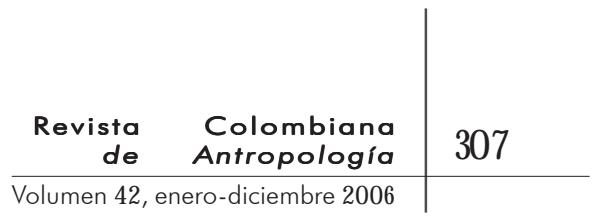

diferente al de Hacienda. Roberto Junguito ha hecho parte de la junta en dos oportunidades, como ministro y como codirector, y dos de ellos, Sergio Clavijo y Leonardo Villar, han ocupado el cargo de viceministro técnico de Hacienda. Cuatro han estado asociados al DNP, ya sea como director (Miguel Urrutia), como subdirectores (Carlos Caballero y Fernando Tenjo) o como jefe de departamento (José Darío Uribe). Y, en general, todos han trabajado en entidades públicas. Su recorrido ha estado marcado por el paso por entes multilaterales. Nueve han estado asociados a organismos multilaterales, cinco de ellos al Banco Interamericano de Desarrollo (BID), dos al Fondo Monetario Internacional (FMI), dos a la Organización de los Estados Americanos (OEA) y uno más al Instituto Iberoamericano de Cooperación para la Agricultura (Iica).

En cuanto al vínculo con la academia y la investigación, encontramos que cuatro de los miembros, Carlos Caballero, Juan José Echavarría, Roberto Junguito y Miguel Urrutia, han ocupado el cargo de director de Fedesarrollo; tres más han estado vinculados como investigadores de esa entidad, entre los cuales Carlos Caballero y Leonardo Villar también se han desempeñado como editores la revista Coyuntura Económica. Cuatro han ocupado una decanatura en la Universidad Nacional de Colombia o en la Universidad de los Andes.

Como vemos, se podría afirmar que quienes acceden a los cargos directivos del Banco de la República tienen un perfil muy particular. Evidentemente, es un perfil con el que se busca una trayectoria que asegure la experiencia necesaria para enfrentarse a un cargo de tan alta responsabilidad. Sin embargo, es útil indagar acerca del prestigio que les adjudica haber ocupado ciertos lugares, los significados de los que están cargados esas prácticas que los llevan al poder y la función legitimadora que poseen.

Empieza a conformarse esa cosa colombiana que es que usted está en Fedesarrollo dos tres años, luego pasa a Planeación un año, luego viene aquí un año (Universidad de los Andes), en Hacienda está dos años y es viceministro allá, director acá, de golpe se vuelve ministro de Educación, de pronto está en Fedesarrollo escampando un año, de golpe se viene aquí de decano dos años (alto miembro del gobierno central en su momento, actualmente dedicado a la academia. Entrevista realizada en marzo de 2004). 
Una práctica muy común en los economistas que hoy en día sustentan el poder ha sido el paso por centros de investigación, particularmente Fedesarrollo. Si bien la rotación incluye entes multilaterales y el sector privado y público, los centros de investigación y la academia tienen la particularidad de fortalecer la imagen de élite intelectual. De manera que se convierte en un hecho muy normal que quienes se encargan de la política económica hayan pasado por centros como Fedesarrollo que, a pesar de no ser una entidad pública, tiene un fuerte vínculo con los hacedores de políticas públicas.

El vínculo de Fedesarrollo con la política económica es muy cercano, es un sitio donde los investigadores entran y salen muy fácilmente del sector público, es un sitio donde básicamente se hacen trabajos de investigación pero los directores de los trabajos casi siempre son personas que han sido ministros, directores de Planeación, consultores o asesores importantes (miembro de la junta directiva del Banco de la República. Entrevista realizada en marzo de 2004).

Algo muy similar sucede con el paso por la academia, ya sea como catedráticos, decanos o investigadores. Estas dos prácticas tienen gran peso en el prestigio y credibilidad que alcancen estos economistas ya que, a pesar de que la rotación en general es un mecanismo para acumular capital social, económico y cultural, el paso por universidades y centros de investigación les permite crear y fortalecer su imagen de expertos, de técnicos que, no sólo tienen exclusividad en el manejo y conocimiento de ciertos asuntos de gran importancia para la nación, sino que cuentan con un carácter académico e intelectual que los aleja de la corrupción política y los intereses particulares.

Si hay algo positivo en Colombia es ese vínculo y esos núcleos que se arman de hacedores de políticas que al mismo tiempo son cercanos a la academia. Eso es muy positivo porque le da un carácter académico a la política, a la política económica. Hay instituciones en el gobierno como Planeación o el Ministerio de Hacienda que han sido tradicionalmente muy técnicas. La experiencia cuando yo estuve allá [en el Ministerio de Hacienda] era que los funcionarios del Ministerio, casi exceptuando al ministro eran técnicos y duraderos, de golpe eso se ha reducido un poquito (miembro de la junta directiva del Banco de la República. Entrevista realizada en marzo de 2004). 


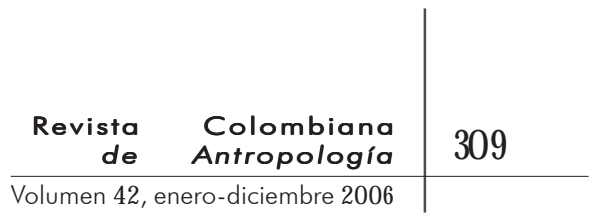

La supuesta neutralidad de sus técnicas les permite mostrarse como funcionarios que, inmunes a las influencias políticas, están en esos cargos para usar fórmulas neutras, producto de investigaciones puramente académicas, realizadas con herramientas que por sus características son ajenas a cualquier interés particular.

La gente que llega a esos ministerios [los encargados de la política económica] en general y empezando por los ministros, no es gente que esté buscando rentas, por ponerlo así. No es la persona que tiene su cuarto de hora, de una vida política el minutico que puede influir en la política económica, sino que es una persona que ha estado influenciando tradicionalmente política económica y que en un momento dado tienen la capacidad de estar influyendo más. Es muy distinto a los ministerios a los que a veces se llega por situaciones de coyuntura política, política digamos, partidista (miembro de la junta directiva del Banco de la República. Entrevista realizada en marzo de 2004).

Con estos argumentos se presentan como funcionarios públicos que, a diferencia de aquellos que se mueven de acuerdo con la "coyuntura y la política partidista", participan en esta arena por un interés puramente intelectual. Este discurso de neutralidad alrededor del cual han ido forjando su imagen los economistas, y que busca alejarse de los sectores conocidos tradicionalmente como políticos, es el discurso sobre el que se fundamentan las corrientes ideológicas dominantes del último siglo, el supuesto sobre el que se cimentó la economía clásica y lo que, entre otras cosas, heredaría más tarde la economía neoclásica.

Imagínese lo difícil que es desmontar ese discurso (...) Aun la gente que hace economía no se da cuenta de eso, se lo creen, creen por ejemplo que la noción utilitarista, en la cual uno ha sido educado, no tiene carga ideológica. Se convencieron de que el cuento era evolutivo y es muy difícil no vender una cosa en la cual uno cree fervientemente (ex ministro, actualmente dedicado al sector financiero. Entrevista realizada en abril de 2004). 


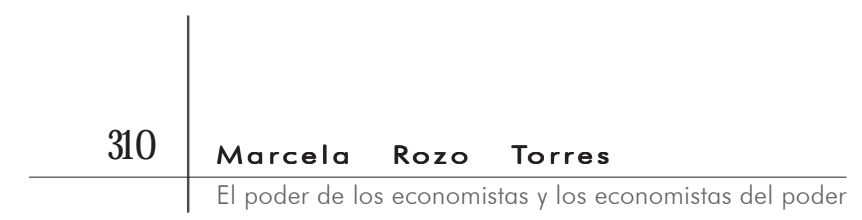

Conclusiones

L FUNDAMENTO TEÓRICO DE LA ECONOMÍA QUE HA DOMINADO EL ÚLTIMO

- siglo, el de la economía clásica y neoclásica, parte de la neL cesidad de establecer a esta disciplina como una ciencia, pretendiendo de esta manera generar un conocimiento libre de juicios de valor que logre explicar la realidad de una manera positiva. Pero este discurso no se ha limitado al ámbito teórico. El proceso mundial de industrialización, así como el desarrollo y rápida expansión de la economía de mercado, han llevado a aceptar las leyes del capitalismo como naturales, por la misma razón que coloca la esfera económica por encima de las otras dentro del sistema capitalista. Esto ha implicado la creación de nuevas prácticas y tradiciones que permiten y validan la consolidación de las nuevas situaciones propias de este sistema.

La importancia que ha cobrado la economía en todas las esferas de lo humano ha implicado que quienes tienen el dominio sobre este discurso y saben manejar sus herramientas cuenten con los elementos para explicar el orden mundial, o por lo menos para decidir cuál es la forma "correcta" de entenderlo. Aun cuando el discurso económico dominante puede, y de hecho es, cuestionado desde diferentes sectores de la sociedad, posee ciertas características que aseguran que la autoridad al respecto permanezca en sus manos, es decir, en manos de los economistas del poder.

El discurso económico se traduce así en una forma particular de leer el mundo, hecho que lo convierte automáticamente en un sistema de control social. Esto significa que los profesionales de la economía superan su condición de técnicos y logran ubicarse en una posición privilegiada, en una posición de poder, gracias a la capacidad que tienen para entender problemas que atañen a toda la población. Sin embargo, el hecho de ser economista no es suficiente en sí mismo para acceder a las altas esferas de poder. En este momento entramos a buscar, primero, quiénes son los economistas del poder y, segundo, cuáles son las prácticas concretas que definen la creación y recreación de este grupo, es decir, las prácticas que limitan el acceso al poder y definen un perfil particular de economista.

La creación de la élite de economistas del poder en Colombia se podría descomponer en dos momentos. Primero, en la justificación teórica que le permite a esta disciplina presentarse como 


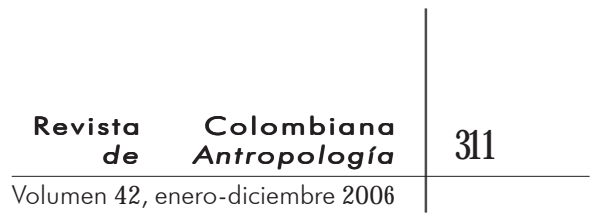

la única capaz de explicar los asuntos más importantes para los gobiernos nacionales. Y segundo, en las prácticas concretas que limitan el acceso a un perfil muy particular de economista.

Por último, al detener nuestra mirada sobre este grupo partimos del hecho que las relaciones de poder están implícitas en las relaciones sociales a cualquier nivel y que, por eso mismo, aparecen y se justifican en cada una de las prácticas que lo conforman. Para hacer explícitas las relaciones de poder dentro del grupo y del grupo con el resto de la sociedad, tomamos como herramienta el estudio del discurso de sus miembros, los argumentos que sustentan a la hora de explicarse a sí mismos y las determinaciones que yacen bajo el lenguaje. Esa fue la idea detrás de las entrevistas realizadas. Y la lectura de estas partió del hecho que las relaciones de poder categorizan al individuo, lo marcan, lo amarran a su propia identidad y le imponen una ley de verdad que él mismo debe reconocer y que los otros deben reconocer en él (Dirks et al., 1994).

\section{BibliogRAFíA}

Ahumada, Consuelo. 1996. El modelo neoliberal y su impacto en la sociedad colombiana. El Áncora Editores. Bogotá.

Bejarano, Jesús Antonio (comp.). 1999. Hacia dónde va la ciencia económica en Colombia. Tercer Mundo. Bogotá.

Benetti, Carlo y Jean Cartelier. 1998. "La economía política como ciencia: la permanencia de una convicción mal compartida”. Lecturas de Economía. 48

Bourdieu, PierRe. 1979(1988). La distinción: criterios y bases sociales del gusto. Taurus. Madrid.

Cataño, José Félix. 1999. "Instituciones y teoría del mercado: las dificultades de Adam Smith". Lecturas de Economía. 50.

Deas, Malcolm. 1993 Del poder y la gramática y otros ensayos sobre historia, política y literatura colombianas. Tercer Mundo. Bogotá.

Dirks, Nicholas et al. (eds.). 1994. Culture/Power/History. A reader in contemporary social theory. Princeton University Press, Princeton.

Dezalay, Yves y Bryant Garth. 2002. La internacionalización de las luchas por el poder. La competencia entre abogados y economistas por transformar los estados latinoamericanos. Universidad Nacional de Colombia. Bogotá. 
Escobar, Arturo. 1988. "Power and visibility: Development and the invention and management of the Third World". Cultural Anthropology. 3 (4).

Friedman, Milton. 1962 (1966). Capitalismo y Libertad. Rialp. Madrid.

Locke, JoHn. 1690 (1963). Ensayo sobre el gobierno civil. Traducción de Armando Lázaro Ros. Aguilar. Buenos Aires.

MarkofF, John y Verónica Montecinos. 1994. "El irresistible ascenso de los economistas". Revista Desarrollo Económico. 34 (133).

Palacios, Marco. 2001 De populistas, mandarines y violencias: luchas por el poder. Planeta. Bogotá.

1999. Parábola del liberalismo. Norma. Bogotá.

Polanyi, Karl. 1944 (2003). La gran transformación: los orígenes políticos y económicos de nuestro tiempo. Fondo de Cultura Económica. México .

Portafolio. 2004. "Se abre baraja en el Emisor”. 26 de abril de 2004.

SAMUels, WARREN. 1988. "An essay on the nature and significance of the normative nature of economics". Journal of Post Keynesian Economics. 10 (3).

Smith, Adam. 1776 (1958). La riqueza de las Naciones. Traducción de Gabriel Franco. Fondo de Cultura Económica. México.

Stiglitz, Joseph. 1993 Economía. Traducción de María Esther Robasco. Ariel. Barcelona.

Recibido: 11de octubre de 2006.

Aprobado: 23de noviembre de 2006. 
TABLA 1

PRINCIPALES CARGOS OCUPADOS POR LOS ECONOMISTAS ENTREVISTADOS

\begin{tabular}{|c|c|}
\hline PREGRADO & - Universidad de New Hampshire \\
\hline MAESTRÍA O DOCTORADO & - New School for Social Research, Nueva York \\
\hline CARGOS GUBERNAMENTALES & $\begin{array}{l}\text { - Codirector, junta directiva del Banco de la República } \\
\text { - Dane }\end{array}$ \\
\hline ACADEMIA E INVESTIGACIÓN & $\begin{array}{l}\text { Decano Facultad de Ciencias Económicas, } \\
\text { Universidad Nacional de Colombia } \\
\text { - Profesor de economía, Universidad Nacional } \\
\text { - Investigador asociado al Cinep } \\
\text { - Investigador visitante en el Institute for Development } \\
\text { Studies, University of Sussex, Inglaterra }\end{array}$ \\
\hline \multicolumn{2}{|l|}{ Roberto Junguito } \\
\hline Pregrado & - Universidad de los Andes \\
\hline MAEstría O DOCTORADO & - Universidad de Princeton \\
\hline CARGOS GUBERNAMENTALES & $\begin{array}{l}\text { - Ministro de Hacienda y Crédito Público } \\
\text { - Codirector junta directiva, Banco de la República } \\
\text { - Embajador de Colombia en Francia } \\
\text { - Ministro de Agricultura } \\
\text { - Misión finanzas intergubernamentales }\end{array}$ \\
\hline ACADEMIA E INVESTIGACIÓN & - Director de Fedesarrollo \\
\hline ENTES MULTILATERALES & - Director ejecutivo alterno, FMI \\
\hline \multicolumn{2}{|l|}{ Miguel Urrutia } \\
\hline Pregrado & - Universidad de Harvard \\
\hline MAESTRÍA O DOCTORADO & - Universidad de Berkeley \\
\hline CARGOS GUBERNAMENTALES & $\begin{array}{l}\text { - Gerente general, Banco de la República } \\
\text { - Ministro de Minas y Energía } \\
\text { - Director, DNP } \\
\text { - Subgerente técnico, Banco de la República }\end{array}$ \\
\hline ACADEMIA E INVESTIGACIÓN & $\begin{array}{l}\text { - Director ejecutivo, Fedesarrollo } \\
\text { - Investigador, CID Universidad Nacional de Colombia } \\
\text { - Director del Cede, Universidad de los Andes } \\
\text { - Director de estudios socioeconómicos, CAR } \\
\text { - Profesor de economía, Universidad de los Andes } \\
\text { y Universidad Nacional de Colombia }\end{array}$ \\
\hline ENTES MULTILATERALES & $\begin{array}{l}\text { - Gerente departamento de desarrollo económico } \\
\text { y social, BID } \\
\text { - Vice rector estudios de desarrollo, Universidad } \\
\text { de las Naciones Unidas en Tokio }\end{array}$ \\
\hline
\end{tabular}




\begin{tabular}{|c|c|}
\hline \multicolumn{2}{|l|}{ Carlos Caballero } \\
\hline PREGRAdo & - Universidad de los Andes \\
\hline \multirow[t]{2}{*}{ MAESTRÍA O DOCTORADO } & - Universidad de Berkeley \\
\hline & - Universidad de Princeton \\
\hline \multirow[t]{5}{*}{ CARGOS GUBERNAMENTALES } & - Codirector junta directiva, Banco de la República \\
\hline & - Ministro de Minas y Energía \\
\hline & - Presidente, Bancoldex \\
\hline & - Director, Proexport \\
\hline & - Técnico de coordinación presupuestal, DNP \\
\hline \multirow[t]{6}{*}{ ACADEMIA E INVESTIGACIÓN } & - Director ejecutivo, Fedesarrollo \\
\hline & - Investigador, Fedesarrollo \\
\hline & $\begin{array}{l}\text { Editor de la revista Coyuntura Económica, } \\
\text { Fedesarrollo }\end{array}$ \\
\hline & - Presidente, Asociación Bancaria \\
\hline & $\begin{array}{l}\text { - Director del pregrado, Facultad de Administración, } \\
\text { Universidad de los Andes }\end{array}$ \\
\hline & $\begin{array}{l}\text { Director de la Escuela de gobierno, } \\
\text { Universidad de los Andes. }\end{array}$ \\
\hline ENTES MULTILATERALES & - Consultor del BID \\
\hline \multicolumn{2}{|l|}{ Sergio Clavijo } \\
\hline PReGrado & - Universidad de los Andes \\
\hline MAEstría O DOCTORADO & - Universidad de Illinois \\
\hline CARGOS GUBERNAMENTALES & $\begin{array}{l}\text { - Codirector junta directiva, Banco de la República } \\
\text { - Viceministro técnico, Ministerio de Hacienda }\end{array}$ \\
\hline ACADEMIA E INVESTIGACIÓN & $\begin{array}{l}\text { - Profesor de economía, Universidad de los Andes } \\
\text { - Investigador del Cede, Universidad de los Andes } \\
\text { económicas, Banco de la República }\end{array}$ \\
\hline & $\begin{array}{l}\text { Jefe de la división fiscal, investigaciones } \\
\text { económicas, Banco de la República }\end{array}$ \\
\hline ENTES MULTILATERALES & $\begin{array}{l}\text { Economista del departamento del hemisferio } \\
\text { occidental, FMI }\end{array}$ \\
\hline \multicolumn{2}{|l|}{ Fernando Tenjo } \\
\hline Pregrado & - Universidad de los Andes \\
\hline MAESTRÍA O DOCTORADO & - Institute of Social Studies \\
\hline CARGOS GUBERNAMENTALES & $\begin{array}{l}\text { - Codirector junta directiva, Banco de la República } \\
\text { - Subdirección general, DNP }\end{array}$ \\
\hline ACADEMIA E INVESTIGACIÓN & $\begin{array}{l}\text { - Director Cider, Universidad de los Andes } \\
\text { - Profesor, Universidad Nacional de Colombia }\end{array}$ \\
\hline ENTES MULTILATERALES & - Director ejecutivo alterno, BID \\
\hline
\end{tabular}




\begin{tabular}{|c|c|}
\hline \multicolumn{2}{|l|}{ Leonardo Villar } \\
\hline Pregrado & - Universidad de los Andes \\
\hline MAESTRÍA O DOCTORADO & $\begin{array}{l}\text { - Universidad de los Andes } \\
\text { - London School of Economics }\end{array}$ \\
\hline CARGOS GUBERNAMENTALES & $\begin{array}{l}\text { - Codirector junta directiva, Banco de la República } \\
\text { - Viceministro técnico, Ministerio de Hacienda }\end{array}$ \\
\hline ACADEMIA E INVESTIGACIÓN & $\begin{array}{l}\text { - Vicepresidente de investigaciones económicas, } \\
\text { Bancoldex } \\
\text { - Editor de la revista Banca y Finanzas } \\
\text { - Vicepresidente técnico, Asociación Bancaria } \\
\text { - Editor de la revista Coyuntura Económica, } \\
\text { Fedesarrollo } \\
\text { - Investigador Fedesarrollo } \\
\text { - Investigador Cede, Universidad de los Andes } \\
\text { - Profesor, Universidad Nacional de Colombia } \\
\text { y Universidad de los Andes }\end{array}$ \\
\hline \multicolumn{2}{|l|}{ Alberto Carrasquilla } \\
\hline PReGrado & - Universidad de los Andes \\
\hline MAESTRÍA O DOCTORADO & $\begin{array}{l}\text { - Universidad de Illinois } \\
\text { - London School of Economics }\end{array}$ \\
\hline CARGos GUBERNAMENTALES & $\begin{array}{l}\text { - Ministro de Hacienda y Crédito Público } \\
\text { - Gerente técnico, Banco de la República }\end{array}$ \\
\hline ACADEMIA E INVESTIGACIÓN & $\begin{array}{l}\text { Decano Facultad de Economía, Universidad } \\
\text { de los Andes } \\
\text { - Profesor, Universidad de los Andes } \\
\text { - Investigador, Fedesarrollo }\end{array}$ \\
\hline ENTES MULTILATERALES & - Economista principal de investigación, BID \\
\hline \multicolumn{2}{|l|}{ Juan José Echavarría } \\
\hline Pregrado & - Universidad Nacional de Colombia, Medellín \\
\hline MAestría o DOCtORADO & - Universidad de Oxford \\
\hline CARGOS GUBERNAMENTALES & $\begin{array}{l}\text { Codirector junta directiva, Banco de la República } \\
\text { Viceministro de Comercio Exterior }\end{array}$ \\
\hline ACADEMIA E INVESTIGACIÓN & $\begin{array}{l}\text { Director ejecutivo, Fedesarrollo } \\
\text { Profesor, Universidad de los Andes, Universidad } \\
\text { Nacional, Universidad Externado de Colombia, } \\
\text { Universidad de Oxford, Pontificia Universidad } \\
\text { Javeriana } \\
\text { - Director de Investigaciones Económicas, FONNDC } \\
\text { - Decano, Facultad de Ciencias Económicas, } \\
\text { Universidad Nacional de Colombia } \\
\text { - Editor de la revista Estrategia Económica }\end{array}$ \\
\hline ENTES MULTILATERALES & - Consultor, OEA \\
\hline
\end{tabular}




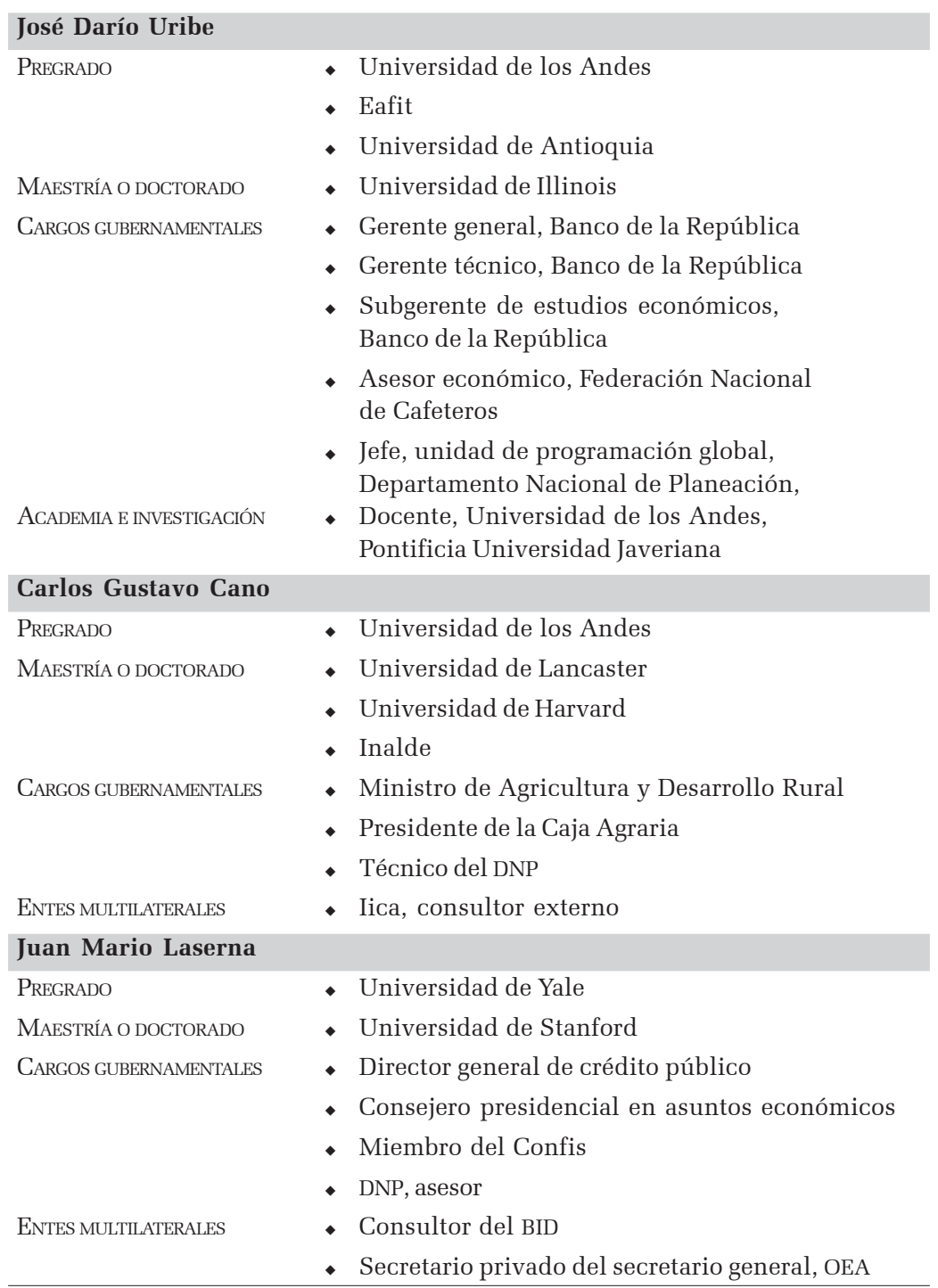

